University of Louisville

ThinkIR: The University of Louisville's Institutional Repository

Electronic Theses and Dissertations

$12-2011$

\title{
Social-emotional behaviors in African-American toddlers : the role of risk and protective factors.
}

Paulette Flores 1970-

University of Louisville

Follow this and additional works at: https://ir.library.louisville.edu/etd

\section{Recommended Citation}

Flores, Paulette 1970-, "Social-emotional behaviors in African-American toddlers : the role of risk and protective factors." (2011). Electronic Theses and Dissertations. Paper 445.

https://doi.org/10.18297/etd/445

This Doctoral Dissertation is brought to you for free and open access by ThinkIR: The University of Louisville's Institutional Repository. It has been accepted for inclusion in Electronic Theses and Dissertations by an authorized administrator of ThinkIR: The University of Louisville's Institutional Repository. This title appears here courtesy of the author, who has retained all other copyrights. For more information, please contact thinkir@louisville.edu. 


\title{
SOCIAL-EMOTIONAL BEHAVIORS IN AFRICAN-AMERICAN TODDLERS: THE ROLE OF RISK AND PROTECTIVE FACTORS
}

\author{
By \\ Paulette Flores \\ B.A., University of Belize, 1996 \\ M.A., University of Louisville, 2007

\begin{abstract}
A Dissertation
Submitted to the Faculty of the

In Partial Fulfillment of the Requirements

For the Degree of

Doctor of Philosophy

Department of Psychological and Brain Sciences

University of Louisville

Louisville, Kentucky
\end{abstract} \\ College of Arts and Sciences of the University of Louisville
}

December 2011 
Copyright 2011 by Paulette Flores

All Rights Reserved 
SOCIAL-EMOTIONAL BEHAVIORS IN AFRICAN-AMERICAN TODDLERS: THE ROLE OF RISK AND PROTECTIVE FACTORS

\section{By}

Paulette Flores

B.A., University of Belize, 1996

M.A., University of Louisville, 2007

A Dissertation Approved on

August 29,2011

by the following Dissertation Committee:

Barbara Burns, Dissertation Director

Janet Woodruff-Borden

Cara H. Cashon 


\section{DEDICATION}

This dissertation is dedicated to my mother Mrs. Salome Flores, brother Augustine Clement Flores and the memory of my dad, Mr. Augustine Flores. Daddy, even though you are gone, I know you are here in spirit. I love you Dads. 


\section{ACKNOWLEDGEMENTS}

I would like to thank God, for guiding and carrying me through this interesting journey. Prayers have helped me to cope and have been my source of strength throughout my graduate school career. I would like to thank my mentor, Barbara, who without her persistence and dedication, to my success, her love for education, and her love for the advancement of women and children, I would not have been able to complete this dissertation. Barbara, I am entirely grateful to you. Words cannot express how I truly feel. You held my hands and guided me throughout this journey. You are an angel in my life. Thank you so much. I am particularly grateful to my cherished friend Nathan Johnson who walked with me on this entire journey. He was always there when I needed encouragement and was a good voice of reasoning. Many thanks to the members of my dissertation committee for generously giving of their time. Much gratitude goes out to the undergraduates (Chiyonne, Connie, Kinton, Kennetha and Staesha) who spent endless hours recruiting participants, preparing packets and entering data. Thank you to my

friends who have been patient with me when I could not always fulfill my duties as a friend due to the demands of graduate school. A special thank you goes out to the President's Committee on Diversity and Racial Equality as it was through their sponsorship of the research that it was possible to recruit all the participants. Many thanks go to the caregivers and toddlers in this study who willing shared their personal information and time. 
Finally, and most importantly, I would like to thank the members of my family. To my mother, who has believed in me and supported me by listening, encouraging, praying, and offering suggestions. Mom, your prayers have been answered. I love you. To my brother Clem who has taken over much of my responsibilities in order for me to pursue my dream. Thank you Bro, I am entirely grateful to you and I love you. To my beloved aunt, Patricia Benguche, sisters Becky and Julie, nieces Natalie, Brianna, and Amber and nephews Dexter, AJ, Dimitri, Patrick Ryan, and Brian thank you all. I am blessed to have such a supportive family. 


\title{
ABSTRACT \\ SOCIAL-EMOTIONAL-BEHAVIORS IN AFRICAN-AMERICAN TODDLERS: THE ROLE OF RISK AND PROTECTIVE FACTORS
}

\author{
Paulette Flores
}

August 29, 2011

The role of risk and protective factors in the family system on toddlers' socialemotional outcomes was examined by exploring the impact of depression and parenting strategies reported by female primary caregivers on toddlers' social-emotional competence and social-emotional problem behaviors. The goal of the research was to extend knowledge concerning how these risk and protective factors relate to socialemotional outcomes in an urban community sample of African-American families. Participants included 103 African-American women and toddlers. Hierarchical multiple regression analyses examined social-emotional problems and social-emotional competence. Results showed that female primary caregivers' depression and annual income were found to significantly predict ratings of toddlers' social-emotional problems. Results from the analysis of social-emotional competence revealed a different pattern. Parenting strategies measured in terms of family routines and gender of the toddlers significantly predicted ratings of social-emotional competence. The current 
findings that different profiles predicted different aspects of toddlers' social-emotional behaviors suggest that different family processes underlie toddlers' developing socialemotional competence and social-emotional problems. These findings have implications for culturally-sensitive interventions tailored to support social-emotional competence and decrease social-emotional problems in toddlers from African-American families. 


\section{TABLE OF CONTENTS}

PAGE





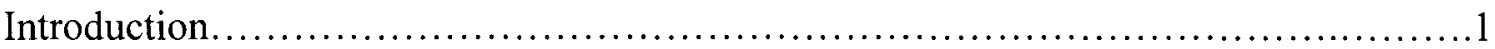

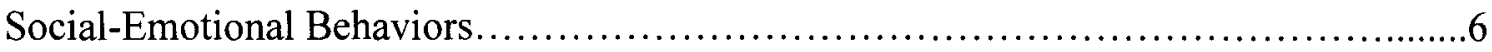

Social-Emotional Behaviors in African-American Toddlers.....................

Social-Emotional Behaviors and Attachment................................9

Social-Emotional Behaviors and Attachment in African-American Toddlers......10

Social-Emotional Behaviors and Social-Emotional Competence...................11

Social-Emotional Behaviors and Social-Emotional Competence in African-

American Toddlers.......................................................... 12

Social-Emotional Behaviors and Social-Emotional Problems..................12

Social-Emotional Behaviors and Social-Emotional Problems in African-American

Toddlers...............................................................



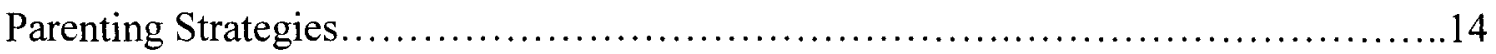

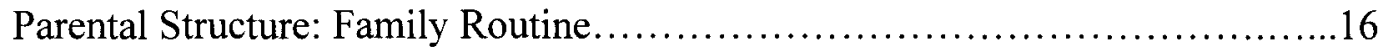

viii 
Parental Structure: Family Routine in African-American Families. .16

Parenting Support and Control........................................ 17

Parenting Support and Control in African-American Families..................17

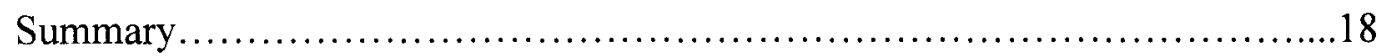

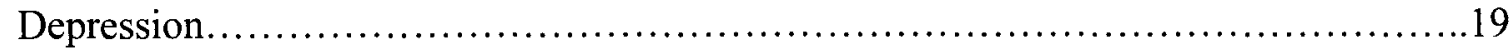

Depression in Women.................................................... 19

Depression in African-American Women...................................20

Ethnic Differences in Depressive Symptoms.............................21

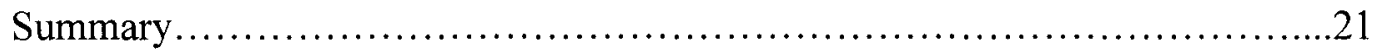

Maternal Depression....................................................... 22

Maternal Depression and Child Outcome.................................23

Maternal Depression and Social-Emotional-Competence in Toddlers............24

Maternal Depression and Social-Emotional Problems in Toddlers...............25



Maternal Depression and Child Outcomes in Toddlers from African-American

Families...............................................................26

Maternal Depression and Social-Emotional Competence in African-American

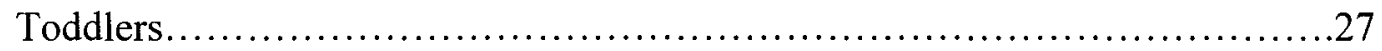

Maternal Depression and Social-Emotional Competence in African-American

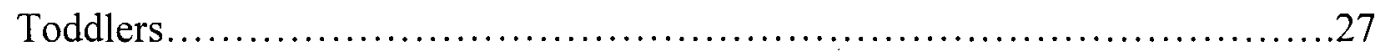

Summary........................................................29 


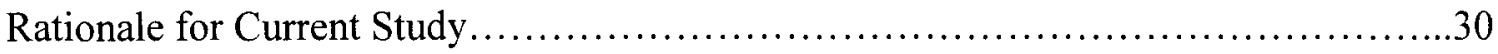

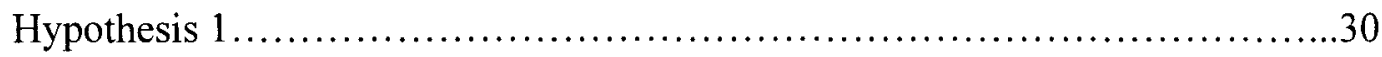

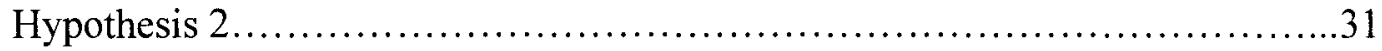



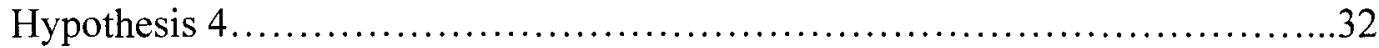

Exploratory Analyses of Depressive Symptoms in African-American

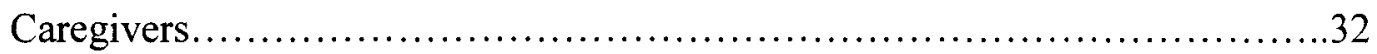

Method

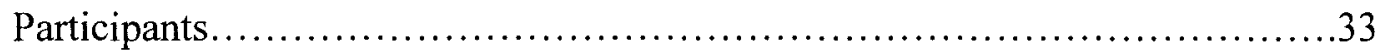

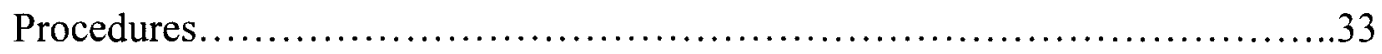

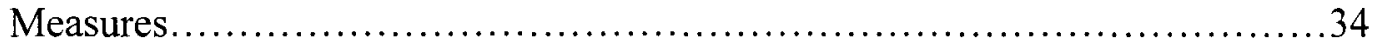

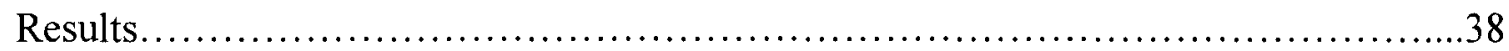

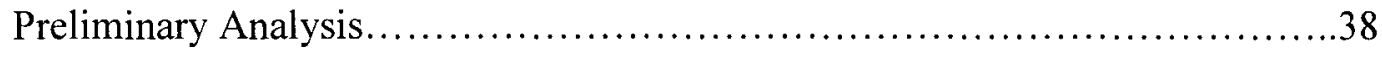

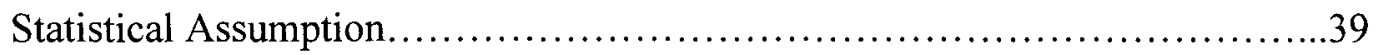

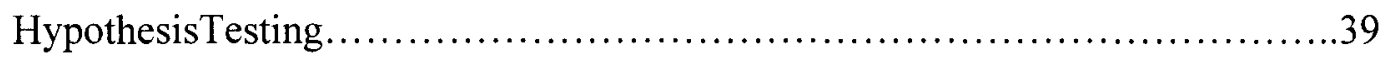

Social-Emotional Problem Behaviors in African-American Toddlers.............40

Summary: Social-Emotional Problem Behaviors in African-American

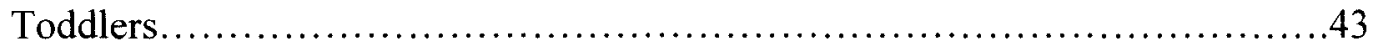

Social-Emotional Competence in African-American Toddlers..................43

Summary: Social-Emotional Competence in African-American Toddlers ........45

Exploratory Analysis................................................... 46 
Follow-Up Analyses on Depression.......................................46

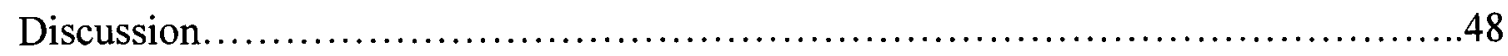

Risk and Protective Factors and Social-Emotional Problems...................49

Risk and Protective Factors and Social-Emotional Competence..................53

Protective Factors as Moderating Variables between Maternal Depression and

Social-Emotional Competence..........................................58

Social-Emotional Problems and Social-Emotional Competence Underlying

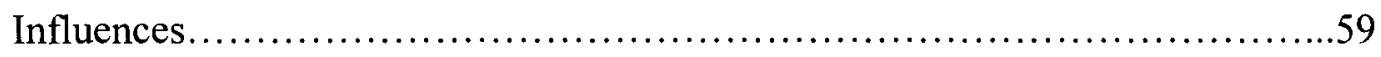







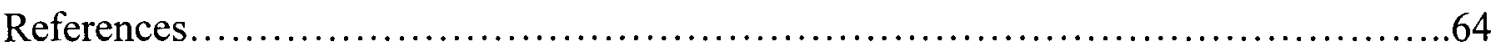

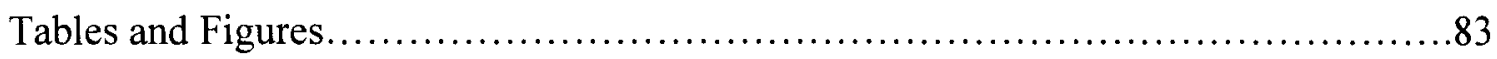

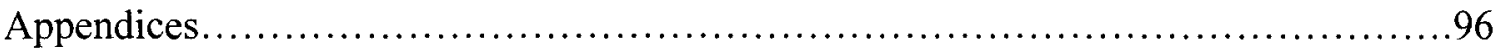

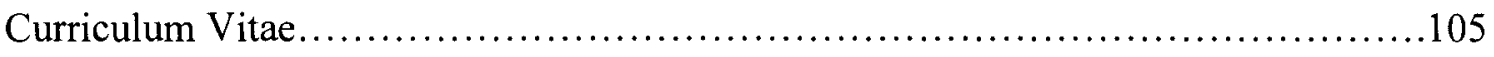




\section{INTRODUCTION}

African-American children have been documented to have challenges in several different domains including cognitive development, social-emotional skills and educational achievement (Yeung \& Pfeiffer, 2009; Brooks-Gunn, Smith, Duncan \& Lee, 2003; Jencks \& Phillips, 1998). In particular, young African-American children are two to three times more likely to be suspended and expelled from school (APA, 2008), and 8.5 times more likely to have parents who are incarcerated (Wildeman, 2007). When compared to Caucasian boys and African-American girls, African-American boys have increased behavior problems and poorer outcomes (APA, 2008).

A great deal of research has supported the idea that central to children's overall success are social-emotional skills. Strong social-emotional skills have been linked to other highly valued outcomes, such as moral development, school adjustment and academic achievement (Dalton, Elias, \& Wandersman, 2007; Haggerty, Sherrod, Garmezy, \& Rutter, 1994; Zins, Weissberg, Wang, \& Walberg, 2004). Deficits in socialemotional skills have been shown to predict early school failure and ongoing school problems, as well as involvement in child welfare, mental health problems and juvenile justice system (Knitzer \& Raver (2002). It is estimated that fifty percent of school-age children lack social-emotional skills, such as appropriately interacting, attending, following directions, empathy and communicating with teachers and peers (Langlois, 
2004; Pianta \& Caldwell, 1990). In addition, children from disadvantaged families are more likely to lag behind in social-emotional skills and also exhibit more socialemotional problems (Achenbach, Howell, Quay, \& Conners, 1991). Furthermore, African-American toddlers from low-income families, are at highest risk for deficits in social-emotional skills when compared to any other group (Graham, Bellmore, \& Mize, 2006).

Despite multiple risk factors and disadvantages (i.e., low-income status, poor neighborhoods, underfunded schools) many African American toddlers have been shown to overcome these adversities (Murry, Bynum, Brody, Willert, \& Stephens, 2001). This is an area of considerable interest from a range of perspectives. Research shows that some family characteristics appear to act as protective factors for the acquisition of social-emotional competence and decrease in social-emotional problems in AfricanAmerican toddlers (Jackson, Brooks-Gunn, Huang, \& Glassman, 2000; Keltner, 1990). Caregiver sensitivity and parenting strategies, such as family routine and parenting structure and control, function as protective factors and buffer the effects of the deficiency in social-emotional skills (Bornstein, Hendricks, Haynes, \& Painter, 2007) Alternatively, primary caregivers' depression characterized by disengagement, hostility, critical and less sensitive caregiver-child interactions has been identified as a risk factor and is associated with deficits in social-emotional skills in both majority (Field, Pickens, Fox, Nawrocki, \& et al., 1995) and minority families (Aikens, Coleman, \& Barbarin, 2008; Koblinsky, Kuvalanka, \& Randolph, 2006b). As noted above, these risk factors can be cumulative. For example, the risk factor of caregivers' depression may add to the risk factor of poverty and both have significant negative effects on the development of social- 
emotional skills as well as other aspects of child development (APA, 2000; Campbell, Cohn, \& Meyers, 1995; Cummings \& Davies, 1994; Petterson \& Albers, 2001). Specifically, poverty has been shown to negatively impact the resources necessary to provide family health (food security, health insurance, affordable housing) (National Center for Children in Poverty, 2009), as well as reduce the structure and routine necessary to provide stability to a family (Child Trend and Data Bank, 2010).

Bronfrenbrenner's ecological/risk and resilience framework, which emphasizes the multiple contributions of the individual and the environment (Bronfenbrenner \& Morris, 1998) has been utilized by many researchers to frame the relationship between risk and protective factors and child outcomes. Child outcomes are predicted on the basis of differential and interactive effects of individual, family, community and larger groups within the society (Bronfenbrenner, 1986). Resilience is viewed as a two-dimensional construct which includes the exposure to risk and protective factors (Luthar \& Cicchetti, 2000). Risk factors are adversities involving negative life issues (e.g. caregiver depression and poverty) that are known to be associated with negative child outcomes. Protective factors are individual or environmental characteristics that provide the ability to resist the effects of risk factors (e.g. parenting strategies) and promote adaptation and competence (Garmezy \& Rutter, 1983; V. Murray \& Brody, 1999).

Bornstein, Hendricks, Haynes, and Painter (2007) expanded on the ecological/risk and resilience model and argued that within the family system which influences the child's development and maternal sensitivity, there are three domains of influence: maternal personal characteristics, child personal characteristics and maternal social context. These three domains are organized in a nested arrangement of distal-to-proximal 
in relation to the child (see Figure 1) with the child's personal characteristics buffered by the mother's personal characteristics and the mother's social context (Bornstein, et al., 2007). The mother's parenting characteristics (i.e., parenting strategies, expectations of parent-child relationship), behaviors, self-perception, attributes, and social context are the factors most proximal to the development of the child and each factor can serve as a buffer to the penetration of other factors. Additional systems (individual, community and larger agencies within society) can also be influential, however, the mother's impact is strongest due to its proximity to day-to-day functioning. Within the ecological/resilience model, the influence of individual, family, or larger community can be described in terms of protective and risk factors that affect the developmental outcome of the child (Garmezy \& Rutter, 1983).

Bronfrenbrenner and Bornstein's model of the ecological/risk and resilience model can be further expanded by assessing the interactive effect of multiple factors from child characteristics, female primary caregiver's characteristics and female primary caregiver's social context in African-American families. Bornstein argued that the simultaneous investigation of multiple factors allows for the unique association between these factors to be identified (see Bornstein, 2007). Few studies have been conducted with the focus on the interactive effect of multiple risk and resilience factors in AfricanAmerican families in regards to toddlers' social-emotional behaviors. The current study extended Bornstein's model to include a sample of biological mothers and female primary caregivers of African-American toddlers. Current research on African-American families shows that eight percent of African-American children do not live with either parent (Child Trends Data Bank, 2010). 
The purpose of the current research was to better understand the role of risk and protective factors in the African-American family system on toddlers' social-emotional outcomes in three novel ways. First, this work examined both risk and protective factors within the same sample in an attempt to examine how specific protective factors related to parenting (aspects of parental structure, support and control) may interact with the risk factor of primary caregiver's depression in predicting child outcomes. Depression is of paramount importance to study as it affects 35.1 million adults in the United States (Kessler et al., 2003) with higher incidents in low-income women (Kessler, McGonagle, Zhao, Nelson, \& et al., 1994; McGrath, Keita, Strickland, \& Russo, 1990; NolenHoeksema, 1990). Approximately 7 million women between the ages of 25 and 40 years are diagnosed with depression in the United States annually (Kessler, 1995). There are many types of depression that can affect caregivers: clinical, dysthymia, manic, seasonal, psychotic and postpartum. Postpartum depression affects the new mother and has an onset around 4 weeks after childbirth, with symptoms such as fluctuation in mood, preoccupation with infant or a disinterest in the newborn, and is a danger to herself and the newborn (APA, 2000). Other types of depression also impact children and child development. Children of caregivers who report depressive symptoms have been shown to be at risk for negative social-emotional outcomes (Goodman \& Gotlib, 1999, 2002; Murray, Halligan, Adams, Patterson, \& Goodyer, 2006; NICHD, 1999).

Second, the study examined child outcomes in terms of both social-emotional competence (i.e. attention, compliance, empathy, pro-social relations) and socialemotional problems (i.e. internalizing, externalizing and dysregulation) (Briggs-Gowan, Carter, Irwin, Wachtel, \& Cicchetti, 2004). Thus, this study has the potential to 
characterize strengths and challenges in child outcomes. Third, the research focused on a community sample of African-American families. The literature examining child outcomes in African-American families from community samples has been quite limited and narrow in scope. This remains an important problem, however, as there have been repeated reports of more negative social-emotional outcomes in low-income AfricanAmerican children, even when other factors such as economics and education have been considered (Aikens, et al., 2008; Harden et al., 2000a; Koblinsky, et al., 2006b; ZahnWaxler, Iannotti, Cummings, \& Denham, 1990). The rationale for this research is that few studies have looked at both risk and protective factors within the same sample of low-income African-American families, and even fewer have focused on socialemotional competences and social-emotional problems, despite their significance as key factors in child development.

In sum, the goal of this research was to better understand the multiple impacts of primary caregivers' depression and parenting strategies and practices on at-risk AfricanAmerican children's social-emotional competence and social-emotional problems. In Figure 2 is shown a schematic model that summarizes the design of this work. The findings from this research will have implications for school readiness of children facing multiple risk factors as well as inform future interventions with African-American families. Following is a review of the variables examined in the study and a speculation of how they may influence children's behavior.

\section{Review of Related Research}

Social-Emotional Behaviors 
Social-emotional skills represent a domain of early childhood development which describes a range of skills necessary to interact with and maintain relationships (Greenspan \& Lewis, 1999). Behavioral components of social-emotional skills have been described in terms of: how the child views himself, others and the world; how the child relates to himself and others; how the child regulates feelings and behaviors and how the child explores and learn from the environment (Kelly, Zuckerman, Sandoval, \& Beuhlam, 2003). The acquisition of social-emotional skills begins the first day of an infant's life and has been shown to be related to attachment, social-emotional competence and social-emotional problems (Greenspan \& Lewis, 1999). The acquisition of socialemotional skills begins within the relationship with the caregiver. As the term implies, "social-emotional" has a social and emotional component to it. Social development emphasizes the influence of family and community socialization in which children learn to adopt and internalize in order to function effectively (Maccoby \& Martin, 1983). Emotional development refers to the growth of capabilities for emotional expression, adjustment and regulation (Maccoby \& Martin, 1983). Both the social and emotional components are integral and are intertwined, as it is the skills of emotional development of the infant that allows for socialization and acculturation to occur (Greenspan, 2002).

\section{Social Emotional Behaviors in African-American Toddlers}

Social-emotional development is important regardless of ethnic and racial background as it is the way that children adopt and internalize norms, values and morals needed to function and socialize effectively in society (Maccoby \& Martin, 1983). However, Elias and Haynes (2008) argued that social-emotional skills and behaviors may be of critical importance for many children from African-American families as they may 
be their means of regulating their emotions despite the many interpersonal difficulties they may be experiencing. It is well established that children from disadvantaged families are more likely to lag behind in social-emotional development both at school and at home (Achenbach, et al., 1991). Young children from low income households are more likely to experience behavioral problems which affect their development (Knapp, Ammen, Arstein-Kerslake, Poulsen, \& Mastergeorge, 2007). The National Center for Children in Poverty (2009) documented that children of color were more likely to experience factors which put them more at risk for deficits in social, emotional and behavioral development. For instance, in early child care settings and learning environment, African-American young children are three to five times more likely to be expelled than their peers (Gilliam, 2005). In addition, African-American young children are overrepresented in the population of maltreated children between the ages of 0-5, and African-American young children are 8.5 times more likely to have a parent incarcerated than a white child (Wildeman, 2007). Finally, African-American young children have been shown to experience lower levels of secure attachment than Asian-American and White children (Chernoff, McPhee \& Park, 2007).

Despite the exposure to multiple risks, some children from African-American families have positive outcomes (Baker, 1999; Kobus \& Reyes, 2000). Some children appear highly resilient and are able to acquire social-emotional competence skills (Wright \& Masten, 2005). Understanding the acquisition of social-emotional skills and behaviors in low-income African-American families is an important topic with numerous questions that need to be addressed. 


\section{Social-Emotional Behaviors and Attachment}

Attachment is the emotional tie that bonds the caregiver and the child together (Bowlby, 1969). Attachments, whether secure or insecure, are vital as the child uses his or her attachments to generalize his expectation of himself and others. In a healthy, secure attachment, the caregiver is a role-model, 'secure base' and a 'safe haven' for the child (Bowlby, 1969; Hoffman, Marvin, Cooper, \& Powell, 2006). Exploration occurs in a secure attachment, as the infant feels safe to explore the physical environment in situations that may be uncomfortable and stressful (Ainsworth, 1972). Erikson and Vygotsky assert that infants and toddlers need a safe, predictable environment in which to explore for healthy development. Additionally, a secure attachment teaches the infant how to interact, respond, regulate, become aware, participate and emotionally understand in healthy ways (Hoffman, et al., 2006). Secure attachments occur when the caregiver is able to meet the needs of the child in a responsive and appropriate manner. Research has continually demonstrated that insecure attachment does not create the environment for exploration to occur (Ainsworth, 1972). The caregiver is not representative of a "safebase", she / he exhibits inconsistent, inappropriate responses to the cues of the infant and is not emotionally and physically available (Egeland \& Erickson, 1993). The insecure attachment relationship often involves maladaptive behavior patterns towards the child such as neglect, abuse, intrusiveness and unresponsiveness. The infant in an insecure relationship may be anxious, avoidant, disoriented and resistant to the caregiver (Ainsworth et al, 1972). Attachment is an important marker for social-emotional development in that the level of security between the dyad can often be related to competence in other domain such as social, emotional and cognitive domains (Gerhardt, 
2004). Secure attachments are mainly related to social-emotional competence while poor attachment can negatively impact children's social-emotional health and development (Gerhardt, 2004). Research has also demonstrated a relationship between attachment relationships, behavioral problems and achievement in school. A meta-analysis comprising of 80 studies found that insecurely attached infants and toddlers were found to exhibit more behavioral problems in externalizing and internalizing behaviors when compared to securely attached children (van Ijzendoorn, Schuengel, \& BakermansKranenburg, 1999). Research supports that the continuous positive, reciprocating and nurturing relationship between the caregiver/mother and the child in a secure relationship serves as building blocks to create social and emotional health and a caregiver/child bond (Kelly, et al., 2003; Landry, Smith, Swank, Assel, \& Vellet, 2001). However, weak maternal attachment can negatively affect children's social-emotional development and health (NCCP, 2009) as the infant does not learn how to respond, engage, and relate in an appropriate and healthy manner (Greenspan, 2002). Recent reports show that up to $40 \%$ of two-year olds in early child care and learning setting had insecure attachment with their mothers (Chernoff, 2007).

\section{Social-Emotional Behaviors and Attachment in African-American Toddlers}

Comparisons of attachment patterns across African-American, White and Asian families show a disproportionate percentage of insecure attachments in African-American mothers and infants (Chernoff, et.al., 2007). It has been argued that strong attachments are weakened due to the stressors affecting low-income African-American mothers. The numerous negative life stressors may include unemployment, conflict in relationship, over-crowding, dangerous neighborhoods, and chronic strain (Linver, Brooks-Gunn, \& 
Kohen, 2002; Mistry, Biesanz, Taylor, Burchinal, \& Cox, 2004; Mistry, Vandewater, Huston, \& McLoyd, 2002).

\section{Social-Emotional Behaviors and Social-Emotional Competence}

Social-emotional competence can be defined as emotion regulation, initiation and maintenance of peer relationships, aggression and conflict control, prosocial behavior, and development of self-efficacy. As the child develops social and emotional skills within the interaction with the caregiver, the child becomes competent in utilizing these skills (Greenspan \& Lewis, 1999). For example the child who is emotionally competent develops a range of behaviors that engages the caregiver. The caregiver responds in a trusting, nurturing and involved manner and the child in turn is able to reciprocate the behavior. The National Research Council and Institutes of Medicine (2000) asserts that children who are socially and emotionally competent are better able to maintain relationships, communicate with others, adjust, do well in school, take on challenging tasks, self-confident and engage better with others. Recent literature agrees on the importance of social-emotional competence (Denham, 2006; Denham et al., 2000) however there is disagreement on the role of social-emotional competence. Some researchers argue that social-emotional competence is the foundation on which other developmental domains, such as cognitive, physical, intellectual and emotional adjustment, are developed (Harniss, Epstein, et al., 1999). Others propose that socialemotional competence cannot be separated from cognitive development and are equally important (Caine \& Caine, 1991). Regardless of the role of social-emotional competence it has been shown that when developed early in childhood, it helps to develop a healthy 
sense of self leading to strengthened resilience and ability to cope in distressing events and emotional difficulties later in life (Garmezy \& Rutter, 1983).

\section{Social-Emotional Behaviors and Social-Emotional Competence in African-}

\section{American Toddlers}

For African-American toddlers, social-emotional competence may be of even higher importance as it could be key to achieving success in several areas including at school (Baker, 1999; Luthar, 1995). Elias and Hayes (2008) asserted that children's abilities to control their emotions when they feel dejected, hopeless, angry or frustrated, can affect school adjustment as well as the receptivity of learning. They argued that in African-American children, higher rates of social and emotional competence supports children's abilities to focus on academic tasks even in the presence of other personal disturbing issues. In a study of 282 predominantly black third graders, Elias and Haynes (2008) confirmed their hypothesis that social-emotional competence had strong influence on academic outcomes during the critical period of academic skill acquisition. They concluded that interventions used to improve academic achievement for disadvantaged children should address social competences and other factors.

\section{Social-Emotional Behaviors and Social-Emotional Problems}

Just as secure attachment is associated with positive outcomes, insecure attachment between a caregiver and a child is related to a host of negative outcomes (Bakermans-Kranenburg, Van Ijzendoorn, \& Juffer, 2005). Lack of nurturing, continuous negative interaction, and insecure attachment have been associated with not just deficits in social-emotional competence but increases in social-emotional problems (Aikens, et 
al., 2008; Harden, et al., 2000a; Zahn-Waxler, Klimes-Dougan, \& Slattery, 2000). Socialemotional problems related to insecure attachment include externalizing behavior (impulsivity, defiance, aggression), internalizing behavior (withdrawal, general anxiety, separation distress) and dysregulation (negative emotionality, sensory sensitivity) (Briggs-Gowan, et al., 2004). Brauner and Stephens (2006) asserted that between 9.5 and 14.2 percent of children between the ages of birth and five years old experience socialemotional problems that negatively affect their functioning development and school readiness (Poverty, 2009). Specific family and environmental factors have been implicated in children's increased vulnerability to social, emotional and behavioral problems (Poverty, 2009). McDonnell and Gold (2003) asserted that toddlers from families with lower levels of family income are more likely to experience behavioral problems that negatively impact their development. Additionally, family risk factors such as caregivers' mental health have been shown to impact caregivers' ability to support children and contribute to toddlers' behavioral problems (Whitaker, Orzol \& Kahn, 2006). Toddlers with environmental and family risk factors are two to three times more likely to experience problems with anxiety, aggression and hyperactivity (Whitker et al., 2006). Race and ethnicity provide additional risk for social-emotional problems in toddlers (Poverty, 2009).

Social-Emotional Behaviors and Social-Emotional Problems in African-American Toddler

As noted above, African-American children have been shown to be at highest risk for social-emotional problems when compared to other groups (Graham, et al., 2006). A large percent of African-American toddlers from low income families do not acquire the 
habits, values and knowledge necessary to function successfully in society (Poverty, 2009). Barbarin (1993) argued that familial, social and community contexts which play a crucial role in social-emotional behavior development are in critical danger and do not function adequately in low-income African-American families. He stated that the potential problems in the low-income African-American families which affect the socialemotional development include lack of resources, unavailability of parental figures, lack of supervision outside of school hours, instability of residence, poor child care and overburdened parents. The combination of economic hardship, limited access to support, psychological burden and limited family support place significant obstacles in the way of healthy social-emotional development of low-income African-American children hence causing social-emotional problems (Barbarin \& Soler, 1993).

\section{Summary}

Social-emotional skills are integral to school readiness, school success, and overall self-control and self- regulation (Caprara, Barbaranelli, Pastorelle, Bandura, \& Zambardo, 2000; Haggerty, et al., 1994). Research has shown that social-emotional skills are of critical importance especially for African-American toddlers (Baker, 1999; Elias \& Haynes, 2008).

\section{Parenting Strategies}

Parenting plays an important role in supporting infants and toddlers' socialemotional development. Research has shown that family risk factors, especially caregiver factors, can impact the ability of the caregivers to support healthy growth and development (Whitaker, Orzol, Kahn, 2006). A great deal of research has shown a link between increased sensitivity of the mother and improved attachment between the dyad 
(Juffer, Bakermans-Kranenburg, \& van Ijzendoorn, 2005; van Ijzendoorn, Juffer, \& Duyvesteyn, 1995). Increased sensitivity and consistent parenting clearly support the formation of secure attachment providing the child with security and control in the environment (Juffer, et al., 2005).

Parenting strategies that are both sensitive to the needs of the toddler's developmental stages and activities, and are open to the developmental tasks that young children must negotiate, have been shown to have particular significance for healthy child outcomes (Bornstein, 1989). Healthy child outcomes include behavioral independence, social facility, self-regulation, emotion regulation, and emotional security (Bornstein, 1989; Bornstein, Tamis-LeMonda, \& Haynes, 1999; Tamis-LeMonda, Bornstein, \& Baumwell, 2001). Parenting strategies have been central to many theories of child development and social-emotional competence (Slater \& Power, 1987). Two key parenting strategies described in the literature to account for the relationship between parents and children behavior are parental structure, and parental support and control (Maccoby \& Martin, 1983; Rollins \& Thomas, 1979). Parental structure is described as parental involvement, parental consistency or predictability and organization (Emery, 1982; Manire \& Power, 1983; Martin, 1981). Previous research has shown that parental structure is critical for child outcomes in African-American families (Jackson, et al., 2000; McGroder, 2000). The parenting strategies of parental support and parental control have been shown to be related. Parental support has been described to include acceptance, warmth, support, hostility, affection, nurturance, neglect, and rejection (Rollins \& Thomas, 1979). Parental control has included nurturance, sensitivity to the 
child's input and a nonrestrictive parenting (Bourg \& Power, 1985; Maccoby \& Martin, 1983; Rickel \& Biasatti, 1982; Rollins \& Thomas, 1979).

\section{Parental Structure: Family Routines}

The existence of family routine is one indicator of parental structure. Family routines ensure predictability, consistency and organization in the home environment (Jensen, James, Boyce, \& Hartnett, 1983; Keltner, 1990). Family routines have been defined as repetitive behaviors that involve two or more family members that occur with predictable regularity. These behaviors provide stability and continuity during stressful periods and promote the cohesion of the family unit, and can occur on a daily, weekly or monthly basis (Jensen, et al., 1983). Several researches have sought to explain the significance of the effectiveness of family routines. Wilon and colleagues (1992) argued that family routines provide structure and allow family members to know their responsibilities and roles. Garmezy and Rutter (1983) argued that the harmony between parents and children serve as an effective buffer against stressors and help to negotiate daily hassles. Jensen and colleagues (1983) reported that children from majority families whose home environment is made up of routinized, predictable activities, exhibited more self-control and self-regulated behavior. There is considerable evidence that family routines in parenting promote children's learning of pro-social relations, compliance, play, and empathy.

\section{Parental Structure: Family Routines in African-American Families}

Parenting structure has been shown to act as a protective factor in low-income African-American families (Brody \& Flor, 1997; Keltner, 1990). In a study of AfricanAmerican preschoolers, Keltner (1990) found increased cooperation and compliance 
associated with reports of increased family routines. In a similar correlational study with children between 6 and 9 years of age, Brody and Flor (1997) found that home environments with more family routines were associated with reduced internalizing behaviors.

\section{Parenting Support and Control}

Aspects of parental support and control measured in terms of behaviors such as nurturing, positive reinforcement, praise, and warmth (Slater \& Power, 1987), have been proposed to set the foundation for the development of several aspects of child growth such as social-emotional competence and self-regulation, as well as language and cognitive skills (Brody \& Flor, 1997; Brody, Flor, \& Gibson, 1999; Murry, Bynum, Brody, Willert, \& Stephens, 2001). Parental support and control has often been measured using the Adult-Adolescence Parenting Index-2 (AAPI-2) (Bavolek \& Keene, 1999). This

measure yields component scales of expectations, empathy, punishment, family roles and independence. In general, aspects of parental control and support measured with the AAPI-2 have been linked to decreased conduct problems (Gardner, Sonuga-Barke, \& Sayal, 1999; Gardner, Ward, Burton, \& Wilson, 2003) in children and improved cognitive and academic success (Estrada, Arsenio, Hess, \& Holloway, 1987; Supplee, Shaw, Hailstones, \& Hartman, 2004). The AAPI-2 was designed to measure the parenting attitudes of adults and adolescents.

\section{Parenting Support and Control in African-American Families}

Parental support and control have also been found to act as protective factors for African-American toddlers and preschoolers who have been raised in difficult and economically-deprived environments (Jackson, et al., 2000; McGroder, 2000). Jackson 
and colleagues examined how maternal education, instrumental support and financial strain affected the mother's psychological functioning, child development and parenting quality (Jackson et al., 2000). They studied 93 black women and their young children and found that elevated levels of maternal depressive symptoms were directly related to parental support and control strategies. Parenting strategies were also associated with child behavior and preschool ability. McGroder (2000) reported similar findings when investigating African-American mothers with preschoolers from low socioeconomic families. McGroder concluded that there was a positive relationship between maternal nurturance related to parenting support and control and the children's social maturity at the child's entry to school.

\section{Summary}

The research literature supports the idea that particular parenting strategies related to structure and support and control are associated with increased social-emotional competence and a reduction in social-emotional problems. These parenting strategies have been shown to be important for both majority and minority families (Brody \& Flor, 1997; Jackson, et al., 2000; Keltner, 1990).

\section{Depression}

Major depression is a crippling and debilitating disorder affecting 121 million people worldwide and between 32.6 and 35.1 million adults in the United States (Kessler, et al., 2003). This disorder imposes considerable burden on individuals and the country at large. In the year 2000 , depression was estimated to cost the United States over $\$ 83$ billion in medical bills, absenteeism from work and benefits to sick employees. Depression affects all genders, races, ethnicities and may begin at any age with an 
average onset age in the mid-20's. It runs in families and reflects an inherited vulnerability. Among first-degree relatives, the disorder is 1.5 to 3 times more common than in the general population (APA, 2000).

The manifesting symptoms of depression are emotional, psychological, physical, cognitive, behavioral or a combination of these. The symptoms include and are not limited to retardation in movement, lack of interest in previously desired activities, sadness, feelings of loss, change in appetite, feelings of low self-worth, and poor concentration (APA, 2000). If left untreated depression can increase medical costs, increase emergency room visits due to self injuries (Greenberg, Stiglin, Finkelstein, \& Berndt, 1993), have potentially negative effects on family relationships due to divorce and separation (Mazure, 2002), increase unemployment, absenteeism, and substance abuse (Weissman, Bruce, Leaf, Florion, \& Holzer, 1991). The risk of suicide is greater during depression, linking depression to premature mortality. Recovery from individual episodes of depression is possible with appropriate treatment but relapse is common and care for an extended period of time is necessary (Kupfer, Frank, Perel, Cornes, \& et al., 1992). The number of prior episodes predicts the likelihood of subsequent episodes with at least $60 \%$ of those with the disorder expected to have a second episode (APA, 2000). Despite the high prevalence of depression, only a small minority of those afflicted are treated. Primary care workers often fail to diagnose the symptoms due to individual differences in patients (Warren, 2002).

\section{Depression in Women}

Depression is a psychological disorder which interferes with the woman's functioning and is the second leading cause of disability in women (Kessler, 1995). 
Approximately 7 million women between the ages of 25 and 40 years are diagnosed with the disorder in the United States annually (Kessler, 1995). According to the World Health Organization, depression represents the greatest disease threat for women when compared to all other diseases (Murray \& Lopez, 1996). In comparison to men, depression in women usually has an earlier onset and the episodes may be of longer duration than in men (APA, 2000). The course of the disorder in women is usually recurrent and is frequently associated with stressful life events. Some risk factors for depression in women include: a family history of mood disorder, loss of a parent by the age of 10 , a childhood history of physical or sexual abuse, and persistent psychosocial stressors (APA, 2000).

\section{Depression and African-American Women}

According to the American Psychological Association report on depression and women, African-American women are reported to be at a greater risk for depression than any other group due to the higher rates of stressors in their lives (McGrath, et al., 1990). These negative life stressors include environmental challenges and lower income, unemployment and chronic strain (Linver, et al., 2002; Mistry, et al., 2004; Mistry, et al., 2002). Little is known about depression in African-American women (Barbee, 1992; Brooks \& Penn, 2003; Worthington, 1992). This lack of research knowledge have been attributed to the fact that African American women rarely seek treatment, are at risk for misdiagnosis, and often withdraw from treatment programs due to their ethnic, cultural and gender needs not being met (Warren, 1994). The treatments and protocols used to treat depression in African-American women have been developed to meet the needs of Caucasian American males. These diagnostic protocols and treatments are then 
generalized to females and ethnic minorities (U.S. Department of Health and Human Services, 1999). Lack of culturally sensitive diagnostic screening tools may consequently lead to misdiagnoses and under diagnoses in African-American women (Brooks, 2003; Snowden, 2003). These problems may also be due to variability in the manifestation of depressive symptoms between African-American women and Caucasian American men (Snowden, 2005).

\section{Ethnic Differences in Depressive Symptoms}

Several studies have explored the differences in depressive symptoms between Caucasian American and African-American women (Barbee, 1994; Brown, Schulberg, \& Madonia, 1996; Myers et al., 2002; Warren, 1994; Weissman, et al., 1991) and have concluded that racial differences exist in the manifestation of depressive symptoms by African-Americans and Caucasian Americans. Both African Americans and Caucasian Americans share important similarities in their core mood symptoms which include, appetite change, low energy, and social withdrawal (Ayalon \& Young, 2003; Reed, McLeod, Randall, \& Walker, 1996). However, there are some salient distinctions between the two groups in symptom presentation (Ayalon \& Young, 2003; Brown, et al., 1996; Myers, et al., 2002; Reed, et al., 1996) . In comparison to Caucasian Americans, African Americans reported more somatic symptoms than mood disorder (Brown, et al., 1996; Myers, et al., 2002). That is, somatization, paranoia (fearfulness), severe sleep disturbance, appetite loss, loss of libido, physical and psychological distress have been shown to be symptoms more commonly reported among African Americans.

\section{Summary}

Two conclusions can be made after reviewing the literature on depression in African-American women. First, the prevalence of depression is high, and second, 
although core symptoms are similar, some salient differences in symptoms exist such that it can be argued that depressed African-American women often exhibit culturebound symptoms (Ayalon \& Young, 2003; Brown, et al., 1996; Myers, et al., 2002; Reed, et al., 1996). Reasons proposed for the difference in depression manifestation and experience between the two groups include cultural experience, and differences in language used to discuss their depression (Barbee, 1994; Waite \& Killian, 2007).

\section{Maternal Depression}

Depression in women has been shown to negatively impact maternal sensitivity and the growth of social-emotional competence in young children (Cummings \& Davies, 1994). Maternal depression has been shown to affect the mother's ability to communicate, read children's cues and respond sensitively to her children (Campbell, Matestic, von Stauffenberg, Mohan, \& Kirchner, 2007b; Cummings \& Davies, 1994). Maternal depression has been associated with hostile, critical, disengaged play and mother-child interactions that are disorganized, avoidant, less communicative, less responsive and less sensitive (Gelfand \& Teti, 1990). Maternal depression has been shown to clearly hamper the mother's ability to nurture and to provide the sensitivity that the child needs (Cummings \& Davies, 1994).

Chronicity of the mother's depression has been linked with disengaged motherchild interactions. In addition, it has been shown that the more severe the depressive symptoms the mother exhibits, the less sensitive the mother-child interactions (NICHD, 1992). Women who exhibited low, intermittent or chronic depressive symptom were compared and women who reported fewer depressive symptoms were found to be more sensitive to the needs of their children as compared to those who reported chronic depression. 
This study extended the operational definition of "maternal depression" to include female primary caregivers. Thirteen percent of the female primary caregivers in this sample were not biological mothers. Eighty-five percent of these women had been primary caregivers for a minimum of two years (see Whitebook, Phillip, Bellm, Cromwell, Almaraz \& Jo, 2004, for a discussion of depression in female primary caregivers and significance for young children.

\section{Maternal Depression and Child Outcomes}

Maternal depressive symptoms have been shown to impact a range of child outcomes including aspects of attachment and cognition (Lyons-Ruth, 1996; Lyons-Ruth, Zoll, Connell, \& Grunebaum, 1986a; Radke-Yarrow, Cummings, Kuczynski, \& Chapman, 1985; Spieker \& Booth, 1988). Deficits in attachment are important as there is accumulating evidence that the attachment status between the infant and the caregiver has a significant effect on many aspect of the child's development (Cummings \& Davies, 1995; Lyons-Ruth, 1992; L. Murray \& P. Cooper, 1997; Petterson \& Albers, 2001).

A well-established body of research has demonstrated that maternal depression also impacts aspects of cognitive development (Campbell, Matestic, von Stauffenberg, Mohan, \& Kirchner, 2007a; Cummings \& Davies, 1994; Field, et al., 1995; Goodman \& Tully, 2006; NICHD, 1999; Petterson \& Albers, 2001). Campbell and colleagues recently reported a large longitudinal study showing that poor school performance was found in children with mothers reporting chronic depressive symptoms (Campbell, Matestic, von Stauffenberg, Mohan \& Kirchner, 2007). First graders whose mothers reported increasing and chronic levels of depressive symptoms performed poorly in cognitive testing (Woodcock Johnson) and had negative teacher reports as compared with 
children whose mothers reported low or no depression. The findings also revealed that whenever maternal depression was severe, the children's academic performance was adversely affected in a significant way. Similarly, Lyons-Ruth and colleagues (LyonsRuth, Connell, \& Grunebaum, 1990; 1986b) found that there was a significant relationship between higher levels of depression in mothers and poorer performance on cognitive and linguistic measures compared to children whose mothers were never depressed.

Petterson and Albers (2001) examined the cumulative effects of poverty and maternal depression on child outcomes in 7677 mothers and children. The results showed that chronic maternal depression in poor families had a particularly adverse effect on the cognitive and motor development of children. Specifically, children whose mothers had moderate and severe depression scored lower on the developmental screening (Denver Developmental Screening Test) than children whose mothers had low or no depression. Poverty accentuated the finding. Overall, both chronic maternal depression and poverty jeopardize the development of children's cognitive performance. In another longitudinal study by NICHD researchers (NICHD, 1999) maternal depression and other co-occurring risk factors were examined in relation to mother-child interactions and child cognitive functioning in 1,215 thirty-six month olds. The results revealed that chronically depressive symptoms in mothers were associated with reduced performance in children's cognitive, expressive language and linguistic abilities.

\section{Maternal Depression and Social-Emotional Competence in Toddlers}

Social-emotional competency skills have also shown to be impacted by maternal depression. Dietz and colleagues (Dietz, Jennings, \& Abrew, 2005) examined the effects 
of maternal depression on the skillfulness of toddler's self-assertive strategies in interacting with their caregiver or another female. Results reveal that toddlers exposed to maternal depression demonstrated significantly lowered social-emotional competence skills in their self-assertive strategies compared to toddlers who were not exposed to maternal depression. Additionally, toddlers exposed to more chronic courses of maternal depression exhibited even lower social-emotional competency skills. The overall conclusion was that exposure to maternal depression may interfere with the development of social-emotional competence skills in regards to self-assertive strategies and may also affect the mother-child relationship.

\section{Maternal Depression and Social-Emotional Problems in Toddlers}

In addition to negative impacts on social-emotional competence, research has shown that toddlers who are exposed to maternal depressive symptoms are also at risk for increased social-emotional problems (Zahn-Waxler, et al., 1990; Zahn-Waxler, et al., 2000). As toddlers, the effects of having a depressed mother are withdrawal, irritability, negative emotions and lower activity (Field, et al., 1995; L. Murray \& P. Cooper, 1997). Preschool and elementary school aged children of depressed mothers have been reported to be more irritable; explore, engage, and vocalize less; and exhibit more externalizing and internalizing problems (Alpern \& Lyons-Ruth, 1993; Downey \& Coyne, 1990; Harden, et al., 2000a; Lyons-Ruth, Easterbrooks, \& Cibelli, 1997; Lynne Murray, Stanley, Hooper, King, \& et al., 1996; Zahn-Waxler, et al., 1990).

Alpern and Lyon-Ruth (1993) investigated the relationship between past, current and chronic maternal depressive symptoms and children's social-emotional problems (hostile, anxious, hyperactive, demanding and withdrawn). The results indicated that 
children with symptomatic mothers at infancy and preschool had elevated rates of hostile and aggressive behaviors in the classroom and at home. Additionally, these children had more social-emotional problems, such as elevated anxiety and depressive symptoms, than children whose mothers were never depressed. Similarly, Zahn-Waxler and colleagues (1990) found that there was a significant relationship between higher levels of depression in mothers and externalizing behaviors in their preschoolers. Problems were more frequent and continuity patterns were more evident in children of depressed mothers. These effects of maternal depression have been shown to continue across early childhood and adolescence (Angold \& Rutter, 1992; Kaplan, Hong, \& Weinhold, 1984).

\section{Summary}

Maternal depression has been shown to negatively impact a range of child outcomes, including attachment, cognitive development, social-emotional competence, and social-emotional problems (Campbell, et al., 2007a; Lyons-Ruth, et al., 1986a; NICHD, 1999; Petterson \& Albers, 2001; Radke-Yarrow, et al., 1985; Spieker \& Booth, 1988). Most researchers have suggested that the underlying reasons for these consistent findings are that depressed mothers are unsupportive, less engaging, interact less with their children and are more impatient and intrusive with their children (Cox, Puckering, Pound, \& Mills, 1987; Field, et al., 1995; Gelfand \& Teti, 1990; Goodman \& Emory, 1992; L. Murray \& P. Cooper, 1997; L. Murray \& P. J. Cooper, 1997; Webster-Stratton, 1998).

Maternal Depression and Child Outcomes in Toddlers from African-American Families

Relatively few studies have examined the effects of maternal depression on child development in African-American toddlers. The studies that do exist have also reported a 
link between low-income African-American mothers who report higher levels of depressive symptoms and more social-emotional problems and less social competence skills in their young children.

Maternal Depression and Social-Emotional Competence in African-American Toddlers.

A small set of studies has focused on maternal depression and social-emotional competence in African-American families. Koblinsky et al. (2006) studied 184 AfricanAmerican mothers from Head Start Programs and found that maternal depression was a significant risk factor for children's outcomes in this population. Mothers with higher levels of depression had preschoolers who exhibited decreased social competency skills.

\section{Maternal Depression and Social-Emotional Problems in African-American} Toddlers.

Maternal depression has frequently been shown to be associated with increased likelihood of social-emotional problems in African-American children. Harden and colleagues (2000) examined 155 caregiver-child dyads from a suburban sample of African-American families. African-American women with maternal depression and their children were interviewed using a combination of parent-report, teacher-report, independent observation and child assessment methods. A strong correlation was found between increased maternal depressive symptoms and increased social-emotional behavior problems of preschoolers. This study was important in that it is one of the few studies that gather data from several different sources including parents, teachers, direct observation and child assessment to base its findings.

Aikens, Coleman and Barbarin (2008) investigated the relation of maternal depression and child outcomes and examined families of differing ethnicity. Aikens and 
colleagues examined the prevalence, correlates, and consequences of maternal depression for Caucasian American, African-American, and Latino mothers and their preschoolers. This longitudinal study consisted of 412 parent-child dyads. Using data from both teachers and parents the authors concluded that the behavioral outcomes of low-income African-American infant and toddlers with depressed mothers were worse than Latino and Caucasian American children with depressed mothers. Parent-child conflict was found to be a significant mediating variable between maternal depression and child outcome in African-American families. African-American parents with elevated symptoms of depression reported greater parent-child conflict than non-depressed African-American parents. Furthermore, disadvantaged African-American toddlers whose mothers reported depressive symptoms, exhibited more externalizing and internalizing problems when compared to Latino and Caucasian American families. The results suggest that depression as well as the greater parent-child conflict were significant risk factors for increased behavioral problems exhibited by African-American children.

More recently, Riley and colleagues (Riley et al., 2009) examined the association of maternal depression with the behavioral and emotional problems and adaptive skills of 4-10 year olds of predominately African-Americans and Latino families. In a sample of 133 depressed and non-depressed women from low-income urban communities, mothers, fathers and teachers reported on children's emotional and behavioral problems and adaptive functioning. According to the results, children with depressed mothers had significantly more emotional and behavioral problems in comparison to their counterparts with non-depressed mothers. Additionally, children with depressed mothers exhibited lower adaptive skills. 
Maternal depression in African-American caregivers has frequently been measured using the Center for Epidemiological Studies - Depression (CES-D) and has been found to be valid and reliable. This measure has been extensively used with researchers in community-based surveys (Aikens, et al., 2008; Brody \& Flor, 1997; Jackson, Gyamfi, Brooks-Gunn, \& Blake, 1998a; Koblinsky, et al., 2006b; Radloff, 1977a; Taylor, Seaton, \& Dominguez, 2008). Additionally, growing bodies of literature support the universality of the factor structure of CES-D (Perriera et.al., 2005; Rozario \& Menon, 2010). However, as noted earlier, some researchers have questioned the adequacy of this measure for use with different racial groups due to its measurement variance across these different groups (Perriera, Deeeb-Sossa, Harris, \& Bokeen, 2005). Despite the controversy, the CES-D measure was chosen with the current sample population, given its ability to assess four dimensions (i.e., depressed affect, positive affect, somatic complaints and interpersonal relations) of depression and reliability and validity in several different populations (Rozario \& Menon, 2010).

\section{Summary}

Researchers have reported a great deal of evidence that maternal depression negatively affects child outcomes (Luthar \& Cicchetti, 2000) of African-American children. The ecological/resilience models (Bronfenbrenner, 1986; Luthar \& Cicchetti, 2000) in which the outcome of children has been predicted based on the differential and interactive effects of individual, family, community and larger groups within the society holds great promise for the study of African-American families 


\section{Rationale for Current Study}

Toddlers' social-emotional behaviors have been shown to be related to school readiness and academic success in both majority and African-American children (Estrada, et al., 1987; Supplee, et al., 2004). The current study was designed to address several gaps in the literature related to social-emotional behaviors, both competence and problems, in African-American toddlers. The study was designed such that both risk and protective factors related to the family could be examined within the same study and the focus was directed towards both social-emotional competences and social-emotional problems. African-American caregivers provided both assessments concerning potential risk (depression) and resilience (parenting structure and control) factors in their family, and ratings of their toddlers' social emotional competencies and problems. Four research hypotheses were tested.

Hypothesis 1: Higher levels of depressive symptoms, as measured by the Center for Epidemiologic Studies- Depression (CES-D) in African-American female primary caregivers will predict higher scores on their toddlers' social-emotional problems and lower scores on social-emotional competence as assessed by the Brief Infant-Toddler Social- Emotional Assessment (BITSEA) (Briggs-Gowan, et al., 2004).

This hypothesis was based on studies regarding the association of depressive symptoms and behavior problems in majority families (Campbell, et al., 2007a; Koblinsky, et al., 2006b; NICHD, 1999). Previous studies have concluded that toddlers from majority families whose caregivers report more depressive symptoms exhibit both more behavior problems and lower social-emotional competence (Briggs-Gowan, et al., 2004; Zahn-Waxler, et.al., 1990) 
Hypothesis 2: Higher ratings of family routines, as measured by the Family Routines Inventory, by African-American female primary caregivers will predict lower scores on their toddlers' social-emotional problems and higher scores on socialemotional competence as assessed by the Brief Infant-Toddler Social-Emotional Assessment (BITSEA) (Briggs-Gowan, et al., 2004).

This hypothesis was supported by research on parenting strategies related to family structure or family routines which suggests that increased family structure and routines act as a protective factor for children's social-emotional outcomes (Brody \& Flor, 1997; Jensen, et al., 1983; Keltner, 1990). Specifically, Wilon and colleagues (1992) revealed that increased family routines were associated with more cooperation, compliance and less externalizing behaviors on the part of toddlers. The current hypothesis extended this investigation to examine the effect of family routines on socialemotional competence.

Hypothesis 3: Higher levels of parent support and control, as measured by the Adult-Adolescent Parenting Inventory - 2 (AAPI-2), reported by African-American female primary caregivers will predict lower scores on their toddlers' social-emotional problems and higher scores on social-emotional competence as assessed by the Brief Infant-Toddler Social-Emotional Assessment (BITSEA) (Briggs-Gowan, et al., 2004).

This hypothesis was supported by research showing an association of specific parenting strategies related to parental support and control and decreased overall behavior problems (Jackson, et al., 2000; McGroder, 2000). Previous studies have found that African-American mothers and fathers who reported scores of higher levels of involved 
and parenting strategies had children with fewer behavior problems and higher school achievement (Jackson, et. al., 2000).

Hypothesis 4: Parenting strategies, as measured in terms of parenting structure (family routines) and parenting support and control (AAPI-2) will moderate the predictive relationship between maternal depression and social-emotional competence and problems in African-American families.

This hypothesis was supported by previous research linking parenting strategies and child outcomes (Bailey, Delaney-Black, Covington, \& Sokol, 2006; Ceballo, Ramirez, Hearn, \& Maltese, 2003). Previous studies have shown that some parenting strategies moderated the link between child outcomes and distal factors. The current study was designed to extend previous research such that both parental support and control as well as parental structure could be examined in African-American families.

Exploratory Analyses of Depressive Symptoms in African-American Caregivers.

The exploration of somatic depressive symptoms in African-American caregivers will be conducted using items from the CES-D. The exploration of particular symptoms associated with depression in African-American women was supported by studies which suggest that African-American women exhibit different depressive symptoms from majority women (Barbee, 1992, 1994; Brown, Abe-Kim, \& Barrio, 2003; Carrington, 2006). Specifically, these studies have concluded that African-American caregivers exhibit more somatic symptoms of their depression. 


\section{METHODS}

Participants

A total of 103 African-American female primary caregivers with toddlers between ages of 1-3 years were recruited for the study. The toddlers ranged in the age of 12 to 36 months $(\mathrm{M}=25.36, \mathrm{SD}=9.387)$ comprising of 43 boys and 60 girls. Recruitment sites were centered in urban settings in which the population was predominantly low income. As shown in Table 1, the majority of caregivers reported marital status as mostly single (78.6\%), an income of $\$ 8,859$ and below (53.4\%), and the highest grade completed was "some college" $(37.9 \%)$ or "finishing either high school or $11^{\text {th }}$ grade" $(38.8 \%)$.

\section{Procedures}

Caregivers were recruited by distributing information flyers and brochures at places where African-American women convened or visited on a regular basis. These included community mental health agencies, health centers, preschools, beauty salons, low-income neighborhoods, libraries, and transitional residential shelters. Typically, data were collected from caregivers in a one-time twenty minute interview session by the primary researcher. Caregivers completed five questionnaires which measured level of caregiver's depressive symptoms, family routine, child's social-emotional level and parenting strengths and weaknesses. Caregivers received ten dollars and a children's book to compensate for their time and participation. A small number of caregivers had more than one child in that age range. In those cases, one child was chosen randomly as 
the target child. The questionnaires were ordered starting with those dealing with the child assessments followed by parental self report measures of parenting strategies, depression status, and demographics. All procedures were approved by the Institutional Review Board and caregiver informed consent was received prior to data collection.

\section{Measures}

Measures of Child Outcomes

Socioemotional Behavior. The Brief Infant Toddler Social and Emotional Assessment (BITSEA) (Briggs-Gowan, et al., 2004) was used to assess the socialemotional competence and area of difficulties for children between the ages of 12 months and 36 months (Appendix E). The BITSEA has previously been found to be valid and reliable on an ethnically diverse sample population (Briggs-Gowan, et al., 2004). The 49 items on the Problem Scale measures areas of externalizing problems, internalizing problems, problems of dysregulation, maladaptive behaviors, and atypical behaviors. The 11 items on the Competence Scale addresses areas such as attention, compliance, mastery motivation, prosocial peer relations, empathy, imitation and social relatedness.

Responses were rated on a scale of 0 (not true or rarely) to 2 (very true/ often). An option of no opportunity was given for behaviors that a parent had not been given an opportunity to observe in the last month.

The BITSEA yields both a problem score and a competence score. Scoring is done by summing the responses within the problem and competence areas. The child's competence and problem scores are then compared with the cut scores in the appropriate gender and age range. 
Measures of Parenting Strategies.

Parenting Support and Control. The Adult Adolescent Parenting Index 2 (AAPI2) (Bavolek \& Keene, 1999) was used to assess parenting skills and attitudes in 5 categories: expectations of children; parental empathy towards children's needs; use of corporal punishment; parent-child family roles; and children's power and independence (Appendix C). It is has been widely used with low-income and diverse samples of adults and adolesents, including Hawaiians, Mexican-Americans, prison inmates, adolescents, abuse victims, and has been found to be reliable and valid (Bavolek \& Keene, 1999; Cowen, 2001; Palusci, Crum, Bliss \& Bavolek, 2007). This 40-item norm-referenced, standardized measure uses a 5-point Likert scale ranging from strongly agree to strongly disagree. The raw scores were converted to sten scores (or standard scores) that range from 1 to 10 . Previous research has shown that low sten scores (1-3) generally indicate a high risk for abusive parenting, and high sten scores ( 8 to 10 ) generally indicate positive and nurturing parenting. Scores falling in the range of 4 to 7 indicate a moderate risk for abusive parenting. The raw scores for all the participants were scored according to AAPI2 specifications such that five categories and five sten scores for each participant was generated. The mean of the five sten scores was calculated and used for the purpose of this study.

Family Routine Scale (FRI). Routines of the family were measured using seven items from the larger Family Routine Inventory (FRI) (Jensen, et al., 1983). The seven items (Appendix D) chosen, focus directly on activities that occur between a young child and the family. The items were on a scale from 1 (almost never) to 4 (almost always). The FRI has been found to be reliable and valid when used with African-American parent 
and child dyads (Baez, 2000; Brody \& Flor, 1997; Koblinsky, et al., 2006b; Taylor, et al., 2008). Total scores were calculated by summing the scores for the seven items.

Measures of Parent Factors

Parent Demographic Information Form. Background information including age, employment, income, etc. was obtained from each primary caregiver (see Appendix A).

Maternal Depression. Maternal depression was assessed using The Center for Epidemiologic Studies - Depression - CES-D (Radloff, 1977b) (Appendix B). The CESD was used with this sample population as it had previously been used extensively in community sample surveys and has been found to be reliable and valid with AfricanAmerican women (Aikens, et al., 2008; Brody \& Flor, 1997; Jackson, et al., 1998a; Koblinsky, et al., 2006b; Radloff, 1977a; Taylor, et al., 2008). The 20-item assessment measured the acute and current level of depressive symptoms with an emphasis on depressed mood in the last week. This measure incorporates the main symptoms of depression and ranks responses on a 4-point scale. The ranges for the scores were measured on a Likert Scale from 0 (rarely or not at all/ less than I day per week) to 3 (most or all 5 to 7 days per week) with the total score ranging from 0-60. According to previous studies, scores between 16 and 26 are indicative of mild depression, scores of 27 and higher are indicative of higher levels of depressive symptoms (Zich et al., 1990; Ensel, 1986). The assessment rated the frequency within a week period, within which participants have felt "sad", "lonely", "fearful", "guilty", "hopeless" and other depressive symptoms.

Exploratory Analysis of Somatic Dimensions of Depression 
An exploratory analysis was conducted with a subset of the somatic assessment questions on the CES-D. The somatic-related items correspond to questions numbered 1 , $2,5,7,13$, and 20 on the CES-D (Appendix F). These six items had face validity and had an alpha coefficient in this study of .57 . The reliability testing of the six items was conducted to ensure that these items reflected the somatic dimension that they were measuring. 


\section{RESULTS}

\section{Preliminary Analyses}

Means and standard deviations for study variables are shown in Table 2. Preliminary analyses were first conducted to determine the overall pattern of children's social-emotional skills and relations among variables: gender, child's age, caregiver's annual income maternal depression, family routine and parent support and control, socialemotional competence scale, social-emotional problem scale. See Table 3. Preliminary analyses were conducted to examine gender differences in social-emotional problems and social-emotional competence. Independent samples t-test results showed gender differences between female and male toddlers on assessments of social-emotional competence $(\mathrm{t}(101)=-2.04, p=.04$. Preliminary analyses were also conducted to determine whether annual income was related to social-emotional problems and socialemotional competence. Spearman correlation results revealed that annual income was significantly related to toddlers' social-emotional problems, $r_{\mathrm{s}}=-.46, p<.001$. Decreasing annual income was associated with increasing toddlers' social-emotional problems. Annual income was not related to social-emotional competence. All the analyses were conducted using two-tailed tests and a significance level set at $p<.05$. In subsequent analyses, gender and the caregiver's annual income were used as control variables. No significant correlations were found between chronological age and socialemotional competence and social-emotional problems. .

\section{Statistical Assumptions}


All statistical assumptions were examined prior to conducting the analyses. The Variable Type Assumption was met as all the predictor variables were quantitative and the outcome variables were quantitative, continuous and unbounded (i.e., there were no constraints in the variability of the outcome data). The Independence Assumption was met as each value of the outcome variable was independent of the other. The DurbinWatson Test showed that the data met the assumption of independence error for both multiple regression (1.532 for the social-emotional competence scale model and 2.257 for the social-emotional problem scale model). Both values were within the acceptable range of greater than 1 and less than 3 (Fields, 2000). Regarding the assessments, each of the predictors had some variation in value with no two variables having variance of zero (i.e., the Non-Zero Variance Assumption was met). The Linearity Assumption was met as the mean values of the outcome variables for each increment of the predictors were linear. Collinearity statistics (i.e., variance inflation factor (VIF) and the tolerance statistics) indicated that the assumption of multicollinearity was not violated as predictor variables were not highly correlated. For the interaction variables (i.e., Maternal Depression $\times$ Family Routine and Maternal Depression $\times$ Parent Support and Control), multicollinearity was avoided by centering the interaction variables.

\section{Hypotheses Testing}

To test the four hypotheses of the current study, two hierarchical multiple regression were conducted. Analyses of social-emotional competence were examined separately from social-emotional problems as assessed by the BITSEA. Hierarchical multiple regressions were used since they were able to demonstrate the effect of each predictor variable on the outcome variables (Cohen \& Cohen, 1983). Maternal depression, family routine and parent support and control were used as the predictor variables for children's social-emotional behaviors (problem scale and competence). Data 
analyses were conducted using Statistical Package for the Social Sciences (SPSS) version 19.

Given that in the preliminary analysis, gender was correlated with ratings on social-emotional competence, gender was used as a control variable in the first block of the hierarchical regression with social-emotional competence. Similarly, given that in the preliminary analysis, household income was correlated with ratings on socialemotional problems, household income was entered in the first block for the hierarchical regression with social-emotional problems. For the second and remaining blocks, both regression analyses had identical variables. Block two of the regression analyses contained the scores on maternal depression. In the third block, scores on the two assessments of parenting strategies were included as measured by the Family Routine Inventory and the AAPI-2. In the final block of the regression analyses the interaction factors of maternal depression $\times$ family routines and maternal depression $\times$ parent support and control were entered.

Social-Emotional Problem Behaviors In African-American Toddlers

Ratings by female primary caregivers of toddlers' social-emotional problem behaviors were examined in relation to: 1) annual income of caregivers, 2) maternal depression, 3) assessments of parenting strategies 4) interaction variable (maternal depression $\times$ family routine; maternal depression $\times$ parent support and control). As shown in Table 4, the control variable of annual income in the first block significantly predicted the social-emotional problem score $F(1,101)=20.12, p<.001$, accounting for $17 \%$ of the variance. The standardized coefficient for annual income was -.41 which showed that caregivers with lower annual income had toddlers with higher problem 
scores, $t(101)=-4.49, p<.001$. Even within a sample of generally low-income families, household income was a relevant factor in predicting child outcomes.

Hypothesis 1: Higher levels of depressive symptoms, as measured by the Center for Epidemiologic Studies-Depression (CES-D) by African-American female primary caregivers will predict higher scores on their toddlers' social-emotional problems as assessed by the Brief Infant-Toddler Social-Emotional Assessment (BITSEA) (BriggsGowan, et al., 2004).

The first hypothesis of the study was confirmed. Results indicated that maternal depression significantly predicted social emotional problems $F(1,100)=18.89, p<.001$ and accounted for $13.2 \%$ of the variance. The standardized coefficient for maternal depression was .37 , which showed that female primary caregivers with higher depression had toddlers with higher problem scores, $t(100)=4.35, p<.001$.

Hypothesis 2: Higher ratings of family routines, as measured by the Family Routines Inventory, by African-American female primary caregivers will predict lower scores on their toddlers' social-emotional problems as assessed by the Brief InfantToddler Social-Emotional Assessment (BITSEA) (Briggs-Gowan, et al., 2004).

The second hypothesis of the study was not supported. There was no evidence that ratings of parenting strategies as measured by assessment of family routines related to ratings of social emotional problem behaviors $(\beta=-.075, p=.378)$.

Hypothesis 3: Higher levels of parent support and control, as measured by the Adult-Adolescent Parenting Inventory - 2 (AAPI-2), reported by African-American female primary caregivers will predict lower scores on their toddlers' social-emotional problems as assessed by the Brief Infant-Toddler Social-Emotional Assessment (BITSEA) (Briggs-Gowan, et al., 2004). 
This hypothesis was not supported. Reports of parent support and control on the AAPI- 2 by female primary caregivers did not significantly add to the regression model ( $\beta$ $=-.14, p=.12)$.

Hypothesis 4: Parenting strategies, as assessed in terms of parenting structure (family routines) and parenting support and control (AAPI-2) will moderate the relationship between maternal depression and social-emotional problems in AfricanAmerican families.

This fourth hypothesis examined the individual and interactive contribution of specific risk and protective factors to child social-emotional problems. Specifically, it examined whether there was an interaction between maternal depression and socialemotional problem and whether parenting strategies (family routine and parenting support and control) moderated this relationship. The interaction variables created were: maternal depression $\times$ family routine and maternal depression $\times$ parent support and control and were placed in block four of the regression analysis. The interaction variables were centered so as to reduce multicollinearity (Aiken \& West, 1991; Judd \& McClelland, 1989), and the newly created centered data-point variables were then multiplied by each other (i.e., a maternal depression centered data-point was then multiplied by family routine centered data-point to create Maternal Depression $\times$ Family Routine interaction variable).

After considering the effects of income and depression, the interaction variables were not significant. No evidence was found for the suggestion that family routine and parenting support and control changed the effect that maternal depression had on the child's social-emotional problems. 
Summary: Social-Emotional Problem Behaviors in African American Toddlers

In sum, correlational analyses conducted showed that maternal depression, and annual income were correlated with social-emotional problems score. Further analyses using hierarchical multiple regression demonstrated that annual income and maternal depression, were the significant predictors for social-emotional problem behaviors. Results revealed that caregivers with higher levels of depressive symptoms had toddlers with higher problem scores. In addition, as caregivers' income decreased, maternal ratings of toddlers' social-emotional problem scores increased.

A central question of the current study was whether parenting strategies (family routines and parent support and control) moderated the relationship between maternal depression and social-emotional problem scale. The results revealed that after considering the effects of annual income and maternal depression, there was no impact of the interaction variables (maternal depression $\times$ family routine; maternal depression $\times$ parent support and control). No support was found for the proposal that parenting strategies moderated the impact of depression on toddlers' social-emotional problem behaviors (See Table 6).

\section{Social-Emotional Competence in African American Toddlers}

Ratings by female primary caregivers of toddlers' social-emotional competence were examined in relation to: 1) gender, 2) maternal depression, 3) assessments of parenting strategies and 4 ) the interaction variable (maternal depression $\times$ family routine; maternal depression $\times$ parent support and control). As shown in Table 7, the control variable of gender was statistically significant $F(1,101)=4.12, p=.04$, accounting for 4 $\%$ of the variance. The standardized coefficient for gender was .20 which shows that the gender of the child predicted the child's social-emotional competence score. The mean ratings of social-emotional competence for girls was 17.98; the mean ratings for boys was $16.79 t(101)=2.04, p=.04$. 
Hypothesis 1: Higher levels of depressive symptoms, as measured by the Center for Epidemiologic Studies-Depression (CES-D) in African-American female primary caregivers will predict lower scores on social-emotional competence as assessed by the Brief Infant-Toddler Social-Emotional Assessment (BITSEA) (Briggs-Gowan, et al., 2004).

Results indicated that maternal depression was not a significant predictor for toddler's social-emotional competence (see Table 7).

Hypothesis 2: Higher ratings of family routines, as measured by the Family Routines Inventory, by African-American female primary caregivers will predict higher scores on social-emotional competence as assessed by the Brief Infant-Toddler SocialEmotional Assessment (BITSEA) (Briggs-Gowan, et al., 2004).

Results revealed support for the hypothesis that higher levels of family routine predicted higher scores on the social-emotional competence scale. As shown in Table 7, family routine predicted social-emotional competence $F(2,98)=4.08, p=.02$, accounting for $8 \%$ of the variance. The standardized coefficient for family routine was .25. Families who reported more routines also report that their toddlers had higher socialemotional competence, $t(98)=2.60, p=011$.

Hypothesis 3: Higher levels of parent support and control, as measured by the Adult-Adolescent Parenting Inventory - 2 (AAPI-2), reported by African-American female primary caregivers will predict higher scores on social-emotional competence as assessed by the Brief Infant-Toddler Social-Emotional Assessment (BITSEA) (BriggsGowan, et al., 2004). 
The hypothesis that the assessments of parental support and control would predict higher scores on social-emotional competence was not confirmed (see Table 7).

Hypothesis 4: Parenting strategies, as assessed in terms of parenting structure (family routines) and parenting support and control (AAPI-2), will moderate the relationship between maternal depression and social-emotional competence in AfricanAmerican families.

Hypothesis four was not supported. After considering the significant effects of gender and family routine in the regression analysis, the interaction was not significant, suggesting that parenting strategies (family routine and the parent support and control) did not impact the relations between maternal depression and children's social-emotional competence.

\section{Summary: Social-Emotional Competence in African-American Toddlers}

In sum, in the analysis of ratings of social-emotional competence scores, the variables of gender and family routine were found to be statistically significant and predicted social-emotional competence. However, maternal depression and parent support and control were not significant predictors of social-emotional competence. One of the key questions underlying this study was the question as to whether parenting strategies (family routines and parent support and control) moderated the relationship between maternal depression and social-emotional competence. Analyses of the interaction factor, maternal depression $\times$ family routine, maternal depression $\times$ parent support and control, revealed no significant contribution to children's social-emotional competence scores. 
Exploratory Analysis

An exploratory analysis was conducted on the somatic depressive symptoms of the CES-D. The somatic-related items correspond to questions numbered 1, 2, 5, 713 , and 20 on the CES-D.

The results of the exploratory analysis revealed that the somatic complaint items represented a third of the total CES-D score. In this sample, the six somatic depression items were significantly correlated with the full CES-D assessment $r(101)=.79, p<$ .001 . Similar to the analysis of the full roster of depressive symptoms, somatic items were significantly correlated with social-emotional problems $r(101)=.35, p<.001$. Meaning that as caregivers' somatic scores increased, the toddlers' social-emotional problems scores also increased.

The somatic complaints items were compared with the depressed affect dimension of the CES-D and the total CES-D score. When compared with the depressed affect $(M=$ 4.82), the somatic scores had a higher mean $(M=5.90)$. Further analyses showed that the mean of the somatic scores represented $34 \%$ of the total CES-D mean score $(M=17.32)$. These findings reveal that somatic symptoms explained over a third of the depressive symptoms of African-American caregivers in a community sample. Caregivers who reported higher levels of somatic depressive symptoms also reported higher levels of social-emotional problems from their toddlers.

\section{Follow-up Analyses on Depression Variability}

Additional analyses revealed wide variability in the depression profiles of this sample. Approximately half of the sample reported symptoms of depression with scores greater than 16 on the CES-D. These follow-up analyses were conducted so as to further investigate the relationship between depressed caregivers and social-emotional problems 
and social-emotional competence. Follow up analyses were conducted with socialemotional problems as the dependent variable. The Pearson correlation analysis revealed that ratings on social-emotional problem were significantly correlated with maternal depression $r(47)=.33, p=.02$. Higher levels of depressive symptoms were associated with increased ratings of social-emotional problems in toddlers. The regression analysis revealed that social-emotional problems were predicted only by the control variable income $F(1,47)=10.98, p=.002$, accounting for $19 \%$ of the variance. The standardized coefficient for income was -.435 which showed that the lower the income the higher the social-emotional problems. (see Table 8).

Follow up analyses examining social-emotional competence as the dependent variable showed that depression was significantly correlated to family routine $r(47)=$ $.36, p=.01$. Increased family routine scores were associated with increased socialemotional competence in toddlers. The regression analysis revealed that family routine was the only predicting factor for social-emotional competence $F(2,44)=4.89, p=.01$, accounting for $17 \%$ of the variance. The standardized coefficient for family routine was .426. Families who reported more routines also report that their toddlers had higher social-emotional competence. (see Table 9) 


\section{DISCUSSION}

The current study was designed to examine the significance of several variables related to caregivers for social-emotional problems and competencies in African American toddlers from a community sample within Bronfrenbrenner and Bornstein's ecological/risk and resilience framework. By examining both the risk factor of caregivers' depression and the protective factors of parenting strategies (i.e., family routine and parental support and control), new information about their individual significance and how these factors interact to impact child outcomes could be obtained. The rationale for looking at child outcomes in terms of both social-emotional competence (i.e. attention, compliance, empathy, pro-social relations) and social-emotional problems (i.e. internalizing, externalizing and dysregulation) centered on the need to characterize both strengths and challenges in child outcomes in relation to these parenting factors. The rationale for the focus on African-American families from an urban community sample was based on the need to expand the investigation of social-emotional behaviors in African-American children from urban community samples to include more than just negative social-emotional outcomes, such as problem behaviors and clinical diagnosis of externalizing symptoms, and study positive social-emotional outcomes, such as competencies. 
Three questions were addressed in this work. First, how do family risk and protective factors predict social-emotional problems in African-American toddlers? Second, how do family risk and protective factors predict social-emotional competence in African-American toddlers? Third, how do protective factors moderate the effect of risk factors on both social-emotional problems and social-emotional competence? Risk and Protective Factors and Social-Emotional Problems

As reviewed earlier, social-emotional problems in toddlers have been researched more extensively than social-emotional competence. Researchers have shown a strong link between social-emotional problems and negative factors such as insecure attachment, externalizing and internalizing behaviors, lack of nurturance, and continuous negative interaction (Aikens, et al., 2008; Harden, et al., 2000a; Zahn-Waxler, et al., 2000). Additional research by Brauner and Stephens (2006) assert that toddlers experience social-emotional problems that negatively affect their functioning, development and school readiness (Poverty, 2009). Poverty (2009) has concluded that race and ethnicity effectively places toddlers at-risk for social-emotional problems making them two to three times more vulnerable (Poverty, 2009).

Income As A Risk Factor For Social-Emotional Problems Given the previous findings that economic disadvantage in families has been shown to be a risk factor that impacts toddlers' social-emotional growth (Duncan, Brooks-Gunn \& Klebanov, 1994; Knapp, Ammen, Arstein-Kerslake, Poulsen, \& Mastergeorge, 2007), the current study recruited African-American caregivers from an urban community environment. The goal was to examine variations in income even within an economically deprived sample. Previous work has shown that the lower the income, the lower the child's social- 
emotional skills, the less family routines and the greater the reports of emotional and behavioral problems (Thompson, 2002). The current question focused on whether this would also be true in an urban community sample. This was important to study as Duncan and colleagues (1994) found that toddlers in low-income neighborhoods are less likely to engage in family routines, more likely to experience behavioral problems than toddlers from affluent neighborhoods (Knapp et al., 2007) and the level of risk for poor social-emotional outcomes in low-income African-American toddlers can be characterized as alarming (Graham, et al., 2006).

The current study with its focus on an urban community sample allowed an in depth analysis of risk and protective factors within an African-American sample from a predominantly low income population. The current findings showed that income and depression in female primary caregivers were predictive of social-emotional problems in African-American toddlers. These findings support previous research and add new findings to the literature. Previous studies have found that high symptoms of maternal depression were correlated with behavior problems in a sample of African-American, or predominately African-American caregivers (Harden et al., 2000b; Jackson, Gyamfi, Brooks-Gunn, \& Blake, 1998b; Koblinsky, Kuvalanka, \& Randolph, 2006a), but they did not assess both social-emotional problems and social-emotional competence. In only one study by Koblinsky and colleagues, was the role of maternal depression and other factors employed to examine their respective roles in predicting social competence as well as problem behaviors in African-American toddlers. Koblinsky found that lower levels of maternal depressive symptoms were predictive of lower levels of externalizing and internalizing behaviors. Koblinsky et al. shared the conclusion that as mothers become 
more depressed, they likely became less responsive, hostile, critical, and generally less engaged, resulting in children rearing themselves or adopting those withdrawn, troubling behaviors exhibited by the parent. New questions emerge from the current findings regarding the impact of maternal depression on social emotional development in that it was found here that the impact was clear for social-emotional problems but not for socialemotional competence. This difference is interesting and worthy of further exploration.

\section{Maternal Depression in African-American Women}

The current understanding of depression in African-American women has many gaps. In support of the work by Ayalon and Young (2003) the current findings showed that somatic symptoms predicted a reasonable percent of depression in African-American women. However, the current study found no difference in the relations between the full depressive scores and the somatic complaint depressive scores taken from CES-D assessment. The somatic complaint items did correlate with the assessments on socialemotional behaviors. The current study found that the depressive symptoms of AfricanAmerican caregivers comprise largely of somatic complaint symptoms. Further research is needed to explore the relationship between somatic complaint symptoms of AfricanAmerican women and the CES-D.

\section{Parenting Strategies in African-American Caregivers of Toddlers}

The current study revealed some interesting differences in the two assessments of parenting strategies. The first and most frequently employed assessment of parenting strategies, the AAPI-2, was not a significant predictor of social-emotional problems in African-American toddlers. This finding contrast with previous research linking higher levels of involved parenting strategies with fewer behavior problems in older African- 
American children (Jackson et al., 2000; McGroder, 2000). A possible explanation for this finding is that parent responses for the AAPI-2 subscales in this study were found to be in the low to moderate category: parental empathy towards children -3.53 ; expectation of children -4.01 ; parent-child family roles -4.16 ; use of corporal punishment -3.73 ; children's power and independence -4.47 . The scores for this study were mostly in the low to moderate range and that could explain why they were not predictive of either high or low social-emotional problems.

The second aspect of parenting strategies, family routines, was examined as a factor that could predict social-emotional problems in African American toddlers. Selfreports of family routines made by female primary caregivers was also not a significant predictor of social-emotional problems in African American toddlers. This contrasts with previous research linking lack of structure and routine to more social-emotional problems (Keltner, 1990; Baez, 2000). Brody \& Floyd (1997) found that in a sample of older, rural African American children, routine in the home was associated with less externalizing and internalizing behavior. The current study differed from previous work in that it was focused on younger African American children. Findings suggested that for these toddlers from African American families, structured family activities was not relevant for aggressive, anxious, and withdrawn behavior. One can speculate as to what kinds of parenting behaviors, perhaps more one-on-one, direct guidance, nurturance and attention, may be more effective to decrease toddlers' problem behavior. It maybe that some of the supportive qualities from the AAPI-2 (empathy towards children; children's power and independence) may have been necessary to reduce the toddler's problem behavior, however, the amount of parenting support and control was low to moderate. 


\section{Risk and Protective Factors and Social-Emotional Competence}

Few studies have focused on social-emotional competence in children at any age in African American families (Murray \& Brody, 1999). As described earlier, socialemotional competence includes a range of behaviors such as: ability to manage and regulate emotion; relate and trust adults and eventually peers; and work attentively and independently (Poverty, 2005). The importance of studying social-emotional competence comes from findings that show that when social-emotional skills are evident early in life, there are increased healthy child outcomes, including positive sense of self leading to resilience, and increased abilities to cope in emotionally difficult situations and distressing events (Garmezy, 1991; Heckman, 2000; Klien, 2002). Increased socialemotional competence has been shown to enable children to be successful in the face of increased adversity (Luthar \& Cicchetti, 2000). Elias \& Hayes (2008) argued that socialemotional competence may be key to achieving success for low-income African American toddlers as it will allow them to be able to focus and attend to the task at hand while ignoring other stressors in their lives. The literature has identified several factors which are associated with an increase in social-competence: predictable and routine household patterns; parental warmth and family communication; parental efficacy (Brody \& Flor, 1998); parenting practices and being female (Poverty, 2011).

\section{Gender As A Protective Factor For Social-Emotional Competence}

Findings from the current study support recent research which showed that in African-American families being female predicted increased social-emotional competence. African-American school-age females have been shown to possess more social-emotional competence than African-American school age males (Achenbach, 
1991, APA, 2008, Graham, et.al., 2006). Poor social-emotional outcomes in AfricanAmerican school age boys have been related to several other domains, such as rate of school expulsion and overall educational achievement (Brooks-Gunn et.al. 2003; Dexter \& Simons, 2009; Yeung \& Pfeiffer, 2009). A recent study by the National Center for Children in Poverty (2011) examined the racial gap between African-American and Caucasian boys in the areas of cognitive and social-emotional development in early childhood and found that African American boys have significantly lower socialemotional skills when compared to Caucasian boys. Furthermore, the gap started as early as the age of nine months, even when SES and demographic factors were controlled. The National Center for Children in Poverty study attributed these less than desirable findings regarding social-emotional skills in African American boys to caregivers' lack of education and financial resources, increased mental health problems, and diminished educational resources for the toddlers. Other possible reasons for lower social-emotional skills in African-American boys could be the absence of role-models and different expectations for African-American boys and girls. In this sample population more than $78 \%$ of the sample were single women, therefore the male toddlers in these households were lacking of a male role-model. The absence of male role-models in AfricanAmerican communities is a troubling issue and is continually being addressed in the media and in scientific and non-scientific writings. African-American girls have a higher likelihood of having role-models present in their lives than African-American boys. The presence of these role-models provides the opportunity to teach girls how to interact, engage and take on roles and responsibilities from a young age. African-American boys lack such opportunities. 
It can be concluded then that African-American male toddlers from low-income families are faced with several challenges (i.e., high possibility of exhibiting socialemotional problems, underfunded schools, neighborhoods characterized by violence, unemployed parents, and lack of role-models) that they need to overcome in order to conform and operate at a socially appropriate level. African-American male toddlers have to conform to a society and face many adversities. More research is needed to better characterize the effort that is needed to overcome these adversities. Assistance is integral from several areas of society. Interventions from parents, mental health professionals, educators, and researchers are particularly necessary to assist young African-American boys. The findings from this study bring awareness to this issue surrounding the adversities faced by African-American boys from low-income families.

That gender emerged as a significant factor in predicting ratings of socialemotional competence and not social-emotional problems in African-American toddlers in the current study suggests the urgency of work needed to more fully account for the mechanisms and processes underlying social-emotional competence.

\section{Parenting Strategies as a Protective Factor for Social-Emotional Competence}

Only one of the parenting strategies assessments, family routines, as measured by the FRI was a significant predictor of social-emotional competence. African-American toddlers whose families engaged in more family routines were rated as having higher social-emotional competence. The current finding that family routine significantly predicted social-emotional competence in African American toddlers supported previous findings linking family routines to increased social-emotional competences in a range of studies. Most of these previous studies focused specifically on cooperation and 
compliance on the part of toddlers (Brody \& Flor 1997; Garmezy, 1985; Keltner, 1990; Koblinsky et.al., 2006). Most of the more recent work has related family routines to broader assessments of successful child outcomes, such as academic achievement. For example, in the classic study of rural African American children, Brody \& Flor (1997) found a positive link between routine in the home environment with higher levels of academic achievement.

The current study adds to the literature as in the current work the focus was on much younger children. Previous work examined preschoolers between 42-67 months and school-aged children between 6 and 9 years of age (Keltner, 1990; Koblinsky et.al., 2006). One can speculate that as African-American families engage in more family routines and predictable activities, such as attending church, eating together, and regular bedtime, the stability of the home increases and these stable interactions supported the opportunity for children to learn social-emotional competence skills such as self-control, negotiation and learning roles and responsibilities (see also, Garmezy, 1983; Jensen, et.al.,1983; Wilson, et.al., 1992). That this relationship was particularly important for female toddlers is an important research topic for further work. Future work should examine whether this vulnerability for low social-emotional competence associated with African American boys may be buffered by interventions promoting increased family activities which are routine, predictable and structure.

It remains surprising that the assessment of parenting strategies in terms of parent support and control was not a significant predictor of social-emotional competence in African American toddlers. The previous research looking at related parenting behaviors 
and toddlers' behavior and adjustment found a significant relationship. (Jackson, et.al. 2000; McGroder, 2000).

Maternal Depression as a Risk Factor for Social-Emotional Competence

The finding that maternal depression was not significantly associated with social emotional competence in African American toddlers was somewhat surprising. This finding contrasted with previous research focused on toddlers from majority families. In those studies lower levels of maternal depressive symptoms were linked to higher levels of social-emotional competence in toddlers (Campbell, et al., 2007b; Lyons-Ruth, et al., 1986a; Dietz, Jennings, \& Abrew, 2005; NICHD, 1999; Petterson \& Albers, 2001; Radke-Yarrow, et al., 1985; Spieker \& Booth, 1988). Campbell and colleagues (2007) in a study of children between the ages of birth and 7 years of age also examined the trajectories of maternal depression. When mothers were less depressed they exhibited more sensitivity in interactions which led to children becoming more responsive overall and able to engage in more reciprocal play.

Of course, the current study differs from these earlier studies with predominantly Caucasion samples in that the sample population was comprised entirely of African Americans female primary caregivers and toddlers. In addition, in the current assessment the families were recruited from urban community sites. Another key difference is that in the current study the levels of reported overall depression symptoms were not high. Findings from the current research suggest that even mild depression in primary female caregivers can have a powerful effect on toddlers' development. More research is needed to examine whether the level of caregiver depression has differential effects on different social-emotional skills and behaviors. In the current sample, the level of depression, 
although mild, was significant enough to affect social-emotional problems but not socialemotional competence. Research to address questions concerning why exposure to the caregiver's depression did not have an effect on social-emotional competence is needed. Assessing positive interactions with other adults (i.e., teachers or other family members) which may allow the toddlers to develop social-emotional competence would also be necessary. This issue regarding dosage of maternal depression and its effects on child outcomes opens new questions about the roots of early social-emotional competence in African-American toddlers and the significance of caregiver depression levels.

One limitation in the current study is the fact that the CES-D only measures acute depressive symptoms, that is, depression symptoms in the previous week. It is possible that additional assessments may be needed to better measure the full range of the depression in the caregivers, and length of depressive symptoms. Future studies are needed which incorporate other depression assessment measures which assess depression across longer periods of time. Additionally, further development of depression measures which are customized for African-American families are needed.

Protective Factors as Moderating Variables between Maternal Depression and

\section{Social-Emotional Competence}

Few studies have been conducted with the focus on the interactive effect of multiple risk and resilience factors in African- American families in regards to children's social-emotional behaviors overall, and especially in regards to social-emotional competence (Brody \& Flor, 1997, 1998, 1999; Murray \& Brody, 1999). The current study showed that the interaction variables of maternal depression $\times$ family routine and maternal depression $\times$ parent support and control were not significant predictors of 
social-emotional competence. No evidence was found for the hypothesis that family routine and parent support and control moderated the relationship between maternal depression and social-emotional competence. Future work is required to continue this line of investigation.

Social-Emotional Problems and Social-Emotional Competence: Underlying

\section{Influences}

One of the most interesting finding in the current study was the very different profile of findings for the study of toddlers' social-emotional problems and socialemotional competence. These two social-emotional behaviors (problem and competence) were measured using one standardized assessment with two components. The predictive factors for social-emotional problems profile were annual income and maternal depression. In contract, the predictive factors for social-emotional competence were gender and family routine. These different profiles suggest that different family processes underlie toddlers' developing social-emotional competence and social-emotional problems.

Only one study has shown similar findings in a study focused on AfricanAmerican toddlers and their fathers. Mitchell and Cabrera (2009), tested the Abidin Parenting Stress Model and found that children with higher ratings of social-emotional competence, as assessed by the BITSEA, had fathers who were more engaged with their children in didactic activities. Again, continued study of the family differences underlying aspects of social-emotional behaviors are warranted.

\section{Limitations of Current Study}


Whereas the current study enhances our understanding of risk and protective factors in African American toddlers, several limitations should be addressed in future studies. First, the sole informants for the information on toddlers' behavior were the caregivers which could have called into question some caregiver bias in the reporting. No direct ovservations were made of parenting or of child behaviors. Second, there is the possibility that depressed mothers distorted or were less sensitive to the actual socialemotional behaviors of their toddlers due to their own depression. The issue of depressed caregiver's accuracy has been frequently called into question in regards to the child's behavior (Webster-Stratton \& Hammond, 1988). However, Richter (1992) was unable to find evidence of caregiver biases in 17 studies that he reviewed. Richter concluded that while caregiver's reports have their limitations, such reports represent an important and reliable source of information in the assessment of parenting, family routine, parent support and control, depression and demographic information. Third, in the current study, family routine, parent support and control, maternal depression and social-emotional problems and competence were assessed concurrently. Due to this, no casual inference about the relations between variables can be drawn. The question remains unanswered as to whether maternal depression contributed or caused social-emotional problems in toddlers or whether social-emotional problems contributed or caused depression in the caregiver. Longitudinal studies are needed to determine the long-term effects of the risk and protective factors on the social-emotional behaviors of African American toddlers. Finally, the study was limited in its generalizability as the participants were exclusively African-American female caregivers from an urban community. Findings may not be 
applicable to African American families with higher incomes, male caregivers, or majority families.

\section{Implications for Interventions}

One of the important benefits of basic research on risk and protective factors that underlie healthy early social emotional development is the possible new information that can be used to develop or inspire interventions. Developing successful interventions to support social-emotional competence and reduce social-emotional problem behaviors for African American toddlers is of extreme importance. Findings from the current study suggested that there may be different sets of factors that underlie social-emotional problem behaviors and social-emotional competence. Increasing the knowledge of these factors or predictive profiles may have great utility and assist clinicians and educators to explore and improve the profiles that occur between the African American caregivers and toddlers in the caregivers' social context, and with others within the family and the society-at-large. Since the profiles underlying social-emotional problem behaviors and social-emotional competence are different, this suggests to clinicians and educators that social-emotional problems and competence cannot be treated in the same manner. Interventions should be tailored differently to increase social-emotional competence and to decrease social-emotional problems. Although there are a number of evidence-based interventions for the growth of social-emotional competence and decrease of socialemotional problems, currently the format utilized for treating social-emotional competence and social-emotional problems typically is quite similar. A majority of interventions seek to decrease social-emotional problems such that there can be increased 
social-emotional competence (Parent Child Interaction Therapy. 2009; PATHS, 2009; Webster-Stratton, Reid, Hammond, 2001).

The rationale for the current research supported the need for mental health professionals to focus on the mental health problems of caregivers considering that the caregivers' mental health is a part of the personal characteristic which should serve as a buffer for the child (Bornstein, 2007). It has been shown that when caregivers are depressed, children appear to lack a buffer from existing negative effects of neighborhood, gangs and community at-large.

The importance of advancing the research literature on prosocial skills and focusing on vulnerable groups should not be underestimated. The current findings bring attention to the need for the development of programs and policies to strengthen social emotional development in African American toddlers. Culturally sensitive programs which focused on increasing positive parenting skills, caregivers' mental health, and increasing family routine have great promise. More work is needed to characterize the mechanisms and processes underlying why family routines, in particular, enhance socialemotional competence.

\section{Conclusion}

The current research focused on understanding the role of risk and protective factors within the family system on social-emotional outcomes in a sample of lowincome African American caregivers and their toddlers. Results indicated that higher levels of maternal depression and lower income predicted higher levels of socialemotional problems in African American toddlers. The pattern for social-emotional competence differed from this. It was also found that higher levels of family routines 
predicted higher levels of social-emotional competence with girls exhibiting more competence than boys. The factors that predicted social-emotional problems were different from those that predicted social-emotional competence. This finding has both basic science and applied implications and has demonstrated new knowledge on how to conceptualize early social-emotional problems and competence in African-American toddlers. These findings leave open the suggestion that interventions developed to treat social-emotional competence and social-emotional problems in African-American toddlers may need to be tailored quite differently. Given the well-documented deficits in social-emotional behaviors in this population and the importance of social-emotional behaviors for school readiness and academic success, developing more effective interventions to improve social-emotional behaviors in African American toddlers is a worthwhile endeavor 


\section{REFERENCE}

Achenbach, T., Howell, C., Quay, H., \& Conners, C. (1991). National survey of problems and competencies among four- to sixteen-year-olds: Parents' reports of normative and clinical samples. Monographs of the Society for Research and Child Development 56, 5-120.

Aikens, N. L., Coleman, C. P., \& Barbarin, O. A. (2008). Ethnic differences in the effects of parental depression on preschool children's socioemotional functioning. Social Development, 17, 137-160.

Ainsworth, M. D. (1972). Attachment and dependency: A comparison Gewirtz, Jacob L (1972) Attachment and dependency x, 251 pp Oxford, England: V H Winston \& Sons; England.

Alpern, L., \& Lyons-Ruth, K. (1993). Preschool children at social risk: Chronicity and timing of maternal depressive symptoms and child behavior problems at school and at home: Development and Psychopathology 5, 371-387.

American Psychological Association Zero Tolerance Task Force. (2008). Are Zero Tolerance Policies Effective in the Schools?: An Evidentiary Review and Recommendations. American Psychologist 63, 852-862.

Angold, A., \& Rutter, M. (1992). Effects of age and pubertal status on depression in a large clinical sample. American Psychologist 64, 500-514. 
APA, A. P. A.-. (2000). Diagnostic and statistical manual of mental disorders : DSM-IVTR. Washington, D.C.: American Psychiatric Association.

Ayalon, L., \& Young, M. A. (2003). A comparison of depressive symptoms in African Americans and Caucasian Americans. Journal of Cross-Cultural Psychology, 34, $111-124$

Baez, T. (2000). The effects of stress on emotional well-being and resiliency through mediating mechanisms of active coping skills and family hardiness. (coping). The Journal of Clinical Psychology, 45, 102-125.

Baker, J. (1999). Teacher-student interaction in urban at-risk classrooms: Differential behavior, relationship quality, and student satisfaction with school. The Elementary School Journal, 100, 57-70.

Bakermans-Kranenburg, M. J., Van Ijzendoorn, M. H., \& Juffer, F. (2005). Disorganized Infant Attachment and Preventive Interventions: A Review and Meta-Analysis: Infant Mental Health Journal, 26, 191 - 216..

Barbarin, O. A. (1993). Emotional and social development of African American children. Journal of Black Psychology, 19, 381-390.

Barbarin, O. A., \& Soler, R. E. (1993). Behavioral, emotional, and academic adjustment in a national probability sample of African American children: Effects of age, gender, and family structure. Journal of Black Psychology, 19, 423-446.

Barbee, E. L. (1992). African American women and depression: A review and critique of the literature. Archives of Psychiatric Nursing 6, 257-265

Barbee, E. L. (1994). Healing time: The blues and African-American women. Health Care for Women International, 15, 53-60. 
Bavolek, S., \& Keene, R. (1999). Adult-adolescent parenting inventory-2: Administration and development handbook. Park City, UT.: Family Development Resources.

Bornstein, M. H. (1989). Maternal responsiveness: Characteristics and consequences. San Francisco, CA: Jossey-Bass.

Bornstein, M. H., Hendricks, C., Haynes, O. M., \& Painter, K. M. (2007). Maternal Sensitivity and Child Responsiveness: Associations with Social Context, Maternal Characteristics, and Child Characteristics in a Multivariate Analysis. Infancy, 12, 189-223.

Bornstein, M. H., Tamis-LeMonda, C. S., \& Haynes, O. M. (1999). First words in the second year: Continuity, stability, and models of concurrent and predictive correspondence in vocabulary and verbal responsiveness across age and context: Infant Behavior \& Development.

Bourg, T., \& Power, T. (1985). Maternal strategies for compliance in a resistance to distraction task. Paper presented at the bienniel meeting of the Society for Research in Child Development.

Bowlby, J. (1969). Attachment and Loss: Vol.1. Attachment. London: Hogarth.

Briggs-Gowan, M., Carter, A., Irwin, J., Wachtel, K., \& Cicchetti, D. (2004). The Brief Infant-Toddler Social and Emotional Assessment: Screening for Social-Emotional Problems and Delays in Competence. Journal of Pediatric Psychology, 29, 143155. 
Brody, G. H., \& Flor, D. L. (1997). Maternal psychological functioning, family processes, and child adjustment in rural, single-parent, African American families. Developmental Psychology, 33, 1000-1011.

Brody, G. H., Flor, D. L., \& Gibson, N. M. (1999). Linking maternal efficacy beliefs, developmental goals, parenting practices, and child competence in rural singleparent African American families. Child Development, 70, 1197-1208

Bronfenbrenner, U. (1986). Ecology of the family as a context for human development: Research perspectives. Developmental Psychology, 22, 723-742.

Bronfenbrenner, U., \& Morris, P. A. (1998). The ecology of developmental processes. In W. Damon (Ed.), Handbook of child psychology (Vol. 1: Theoretical Models of Human Development, pp. 993-1028). New York: Wiley.

Brooks, A. J., \& Penn, P. E. (2003). Comparing treatments for dual diagnosis: Twelvestep and Self-Management and Recovery Training. American Journal of Drug and Alcohol Abuse, 29, 359-383

Brown, C., Abe-Kim, J. S., \& Barrio, C. (2003). Depression in ethnically diverse women: Implications for treatment in primary care settings: Professional Psychology: Research and Practice 34, 10-19.

Brown, C., Schulberg, H. C., \& Madonia, M. J. (1996). Clinical presentations of major depression by African Americans and whites in primary medical care practice. Journal of Affective Disorders, 41, 181-191.

Campbell, S. B., Cohn, J. F., \& Meyers, T. (1995). Depression in first-time mothers: Mother-infant interaction and depression chronicity. Developmental Psychology $31,349-357$ 
Campbell, S. B., Matestic, P., von Stauffenberg, C., Mohan, R., \& Kirchner, T. (2007a). Trajectories of maternal depressive symptoms, maternal sensitivity, and children's functioning at school entry. Developmental Psychology, 43, 1202-1215.

Campbell, S. B., Matestic, P., von Stauffenberg, C., Mohan, R., \& Kirchner, T. (2007b). Trajectories of maternal depressive symptoms, maternal sensitivity, and children's functioning at school entry. Developmental Psychology 1202-1215.

Caprara, G., Barbaranelli, C., Pastorelle, C., Bandura, A., \& Zambardo, P. (2000). Psychosocial foundations of children's academic achievement. Psychological Science, $11,302-306$.

Carrington, C. H. (2006). Clinical Depression in African American Women: Diagnoses, Treatment, and Research. Journal of Clinical Psychology, Vol 62, 779-791.

Chernoff, J. J. F., K. D.; McPhee, C.; Park, J. (2007). Preschool: First findings from the Third Follow-up of the Early Childhood Longitudinal Study, Birth Cohort (ECLSB). Washington, DC: National Center for Educational Statistics, Institute of Education Sciences, U.S.Department of Education.

Child Trend Data Bank (2010). Family Structure and Living Arrangement. Retrieved August 29, 2011, from: http://www.childtrendsdatabank.org/family.cfm.

Cox, A. D., Puckering, C., Pound, A., \& Mills, M. (1987). The impact of maternal depression in young children. Journal of Child Psychology and Psychiatry, 28, 917-928.

Cummings, E. M., \& Davies, P. T. (1994). Maternal depression and child development. Journal of Child Psychology and Psychiatry, 35, 73-112. 
Cummings, E. M., \& Davies, P. T. (1995). The impact of parents on their children: An emotional security perspective. London, England: Jessica Kingsley Publishers.

Dalton, J., Elias, M., \& Wandersman, A. (2007). Community psychology: Linking individuals and communities. (2 ed.). Belmont, CA: Wadsworth.

Denham, S. A. (2006). Emotional Competence: Implications for Social Functioning Handbook of preschool mental health: Development, disorders, and treatment (pp. 23-44). New York, NY: Guilford Press; US.

Denham, S. A., Workman, E., Cole, P. M., Weissbrod, C., Kendziora, K. T., \& ZahnWaxler, C. (2000). Prediction of externalizing behavior problems from early to middle childhood: The role of parental socialization and emotion expression: Development and Psychopathology 12, 23-45.

Dietz, L. J., Jennings, K. D., \& Abrew, A. J. (2005). Social Skill in Self-Assertive Strategies of Toddlers With Depressed and Nondepressed Mothers. Journal of Genetic Psychology 166, 94-116.

Downey, G., \& Coyne, J. C. (1990). Children of depressed parents: An integrative review. Psychological Bulletin, 108, 50-76.

Egeland, B., \& Erickson, M. (1993). Implications of attachment theory for prevention and intervention Prevention in mental health (pp. 23-50). Lanham, MD: Jason Aronson; US.

Emery, R. (1982). Interparental conflict and the children of discord and divorce. Psychological Bulletin, 92, 310-330. 
Estrada, P., Arsenio, W., Hess, R., \& Holloway, S. (1987). Affective quality of the mother-child relationship: Longitudinal consequences for children's schoolrelevant cognitive functioning. Developmental Psychology, 23, 210-215.

Field, T., Pickens, J., Fox, N. A., Nawrocki, T., \& et al. (1995). Vagal tone in infants of depressed mothers. Development and Psychopathology, 7, 227-231.

Gardner, F., Sonuga-Barke, E., \& Sayal, K. (1999). Parents anticipating misbehavior: An observational study of strategies parents use to prevent conflict with behavior problem children. Journal of Child Psychology and Psychiatry, 40, 1185-1196.

Gardner, F., Ward, S., Burton, J., \& Wilson, C. (2003). Joint play and the development of conduct problems in children: A longitudinal observational study of preschoolers. Social Development, 12, 361-379.

Garmezy, N., \& Rutter, M. (1983). Stress, coping, and development in children. Baltimore, MD: Johns Hopkins University Press.

Gelfand, D. M., \& Teti, D. M. (1990). The effects of maternal depression on children. Child Psychology Review, 10, 329-353.

Gerhardt, S. (2004). Why love matters: How affection shapes a baby's brain: (2004) Why love matters: How affection shapes a baby's brain ix, New York, NY, US: Routledge/Taylor \& Francis Group; US.

Gilliam, W. S. (2005). Prekindergarteners Left Behind: Expulsion Rates in State Prekindergarten Systems. Retrieved December 01, 2009, from http://www.fcdus.org/PDF/NationalPreKExpulsionPaper03.02 new.pdf. 
Goodman, S. H., \& Emory, E. K. (1992). Perinatal complications in births to low socioeconomic status schizophrenic and depressed women. Journal of Abnormal Psychology, 101, 225-229.

Goodman, S. H., \& Gotlib, I. H. (1999). Risk for psychopathology in the children of depressed mothers: A developmental model for understanding mechanisms of transmission. Journal of Abnormal Psychology, 55, 101-112

Goodman, S. H., \& Gotlib, I. H. (2002). Children of depressed parents: Mechanisms of risk and implications for treatment. Washington, DC: American Psychological Association.

Goodman, S. H., \& Tully, E. (2006). Depression in Women Who Are Mothers: An Integrative Model of Risk for the Development of Psychopathology in Their Sons and Daughters. New York, NY: Cambridge University Press.

Graham, S., Bellmore, A., \& Mize, J. (2006). Peer victimization, aggresion and their cooccurance in middle school: Pathways to adjustment problems. Journal of Abnormal Child Psychology, 34, 363-378.

Greenberg, P. E., Stiglin, L. E., Finkelstein, S. N., \& Berndt, E. R. (1993). The economic burden of depression in 1990. Journal of Clinical Psychiatry, 54, 405-418.

Greenspan, S. I. (2002). The secure child: Helping children feel safe and confident in a changing world. Cambridge, MA: Perseus Publishing.

Greenspan, S. I., \& Lewis, N. B. (1999). Building healthy minds: The six experiences that create intelligence and emotional growth in babies and young children. Cambridge, MA: Perseus Publishing. 
Haggerty, R., Sherrod, L., Garmezy, N., \& Rutter, M. (1994). Stress, risk, and resilience in children adolescents: Processes, mechanisms, an interventions. New York: Cambridge University Press.

Harden, B. J., Winslow, M. B., Kendziora, K. T., Shahinfar, A., Rubin, K. H., Fox, N. A., et al. (2000a). Externalizing problems in Head Start children: An ecological exploration. Early Education and Development ,11, 357-385.

Harden, B. J., Winslow, M. B., Kendziora, K. T., Shahinfar, A., Rubin, K. H., Fox, N. A., et al. (2000b). Externalizing problems in Head Start children: An ecological exploration. Early Education and Development, 11, 357-385.

Hoffman, K. T., Marvin, R. S., Cooper, G., \& Powell, B. (2006). Changing Toddlers' and Preschoolers' Attachment Classifications: The Circle of Security Intervention. Journal of Consulting and Clinical Psychology, 74, 1017-1026.

Jackson, A. P., Brooks-Gunn, J., Huang, C.-C., \& Glassman, M. (2000). Single mothers in low-wage jobs: Financial strain, parenting, and preschoolers' outcomes. Child Development 71, 1409-1423.

Jackson, A. P., Gyamfi, P., Brooks-Gunn, J., \& Blake, M. (1998a). Employment status, psychological well-being, social support, and physical discipline practices of single Black mothers. Journal of Marriage \& the Family 60, 894-902

Jensen, E. W., James, S. A., Boyce, W. T., \& Hartnett, S. A. (1983). The Family Routines Inventory: Development and validation. Social Science \& Medicine, 17, 201-211.

Juffer, F., Bakermans-Kranenburg, M. J., \& van Ijzendoorn, M. H. (2005). The importance of parenting in the development of disorganized attachment: Evidence 
from a preventive intervention study in adoptive families. Journal of Child Psychology and Psychiatry, 46, 263-274.

Kaplan, S. L., Hong, G. K., \& Weinhold, C. (1984). Epidemiology of depressive symptomatology in adolescents.

Kelly, J., Zuckerman, T., Sandoval, D., \& Beuhlam, K. (2003). Promoting First Relationships: A curriculum for service providers to help parents and other caregivers meet young children's social and emotional needs. Seattle: NCASTAVENUW Publication.

Keltner, B. (1990). Family characteristics of preschool social competence among Black children in a Head Start program. Child Psychiatry \& Human Development, 21, 95-108.

Kessler, R. C. (1995). The national comorbidity survey: Preliminary results and future directions. International Journal of Methods in Psychiatric Research, 5, 139-151.

Kessler, R. C., Berglund, P., Demler, O., Jin, R., Koretz, D., Merikangas, K. R., et al. (2003). The epidemiology of major depressive disorder: Results from the National Comorbidity Survey Replication (NCS-R). JAMA: Journal of the American Medical Association, 289, 3095-3105.

Kessler, R. C., McGonagle, K. A., Zhao, S., Nelson, C. B., \& et al. (1994). Lifetime and 12-month prevalence of DSM-III--R psychiatric disorders in the United States: Results from the National Comorbidity Study. Archives of General Psychiatry, 51, 8-19.

Knapp, P. K., Ammen, S., Arstein-Kerslake, C., Poulsen, M. K., \& Mastergeorge, A. (2007). Feasibility of Expanding Services for Very Young Children in the Public 
Mental Health Setting. Journal of the American Academy of Child \& Adolescent Psychiatry, 46, 152-161.

Koblinsky, S. A., Kuvalanka, K. A., \& Randolph, S. M. (2006a). Social skills and behavior problems of urban, African American preschoolers: Role of parenting practices, family conflict, and maternal depression. American Journal of Orthopsychiatry, 76, 554-563.

Koblinsky, S. A., Kuvalanka, K. A., \& Randolph, S. M. (2006b). Social Skills and Behavior Problems of Urban, African American Preschoolers: Role of Parenting Practices, Family Conflict, and Maternal Depression. American Journal of Orthopsychiatry, $176,554-563$.

Kobus, K., \& Reyes, O. (2000). A descriptive study of urban Mexican American adolescents' perceived stress and coping. Hispanic Journal of Behavioral Sciences, 22, 163-178.

Kupfer, D. J., Frank, E. F., Perel, J. M., Cornes, C., \& et al. (1992). Five-year outcome for maintenance therapies in recurrent depression. Archives of General Psychiatry, 49, 769-773.

Landry, S. H., Smith, K. E., Swank, P. R., Assel, M. A., \& Vellet, S. (2001). Does early responsive parenting have a special importance for children's development or is consistency across early childhood necessary? Developmental Psychology, 37, $387-403$.

Langlois, J. (2004). Emotion and emotion regulation: From another perspective. Child Development, $75,315-316$. 
Linver, M. R., Brooks-Gunn, J., \& Kohen, D. E. (2002). Family processes as pathways from income to young children's development. Developmental Psychology, 38, $719-734$

Luthar, S. (1995). Social competence in the school setting: Prospective cross-domain associations among inner-city teens. Child Development, 66, 416-429.

Luthar, S., \& Cicchetti, D. (2000). The construct of resilience: Implications for interventions and social policies. Development and Psychopathology 12,857885.

Lyons-Ruth, K. (1992). Maternal depressive symptoms, disorganized infant-mother attachment relationships and hostile-aggressive behavior in the preschool classroom: A prospective longitudinal view from infancy to age five. Rochester, NY: University of Rochester Press.

Lyons-Ruth, K. (1996). Attachment relationships among children with aggressive behavior problems: The role of disorganized early attachment patterns Journal of Consulting and Clinical Psychology 64, 64-73.

Lyons-Ruth, K., Connell, D. B., \& Grunebaum, H. U. (1990). Infants at social risk: Maternal depression and family support services as mediators of infant development and security of attachment. Child Development, 61, 85-98.

Lyons-Ruth, K., Easterbrooks, M. A., \& Cibelli, C. D. (1997). Infant attachment strategies, infant mental lag, and maternal depressive symptoms: Predictors of internalizing and externalizing problems at age 7 Developmental Psychology 33 , 681-692. 
Lyons-Ruth, K., Zoll, D., Connell, D., \& Grunebaum, H. U. (1986a). The depressed mother and her one-year-old infant: Environment, interaction, attachment, and infant development. New Directions for Child Development, 34, 61-82.

Lyons-Ruth, K., Zoll, D., Connell, D., \& Grunebaum, H. U. (Eds.). (1986b). The depressed mother and her one-year-old infant: Environment, interaction, attachment, and infant development. San Francisco: Jossey-Bass.

Maccoby, E., \& Martin, J. (1983). Socialization in the context of the family: Parent-child interation. In P. H. Mussen (Ed.), Handbook of child psychology (Vol. 4, pp. 1101). New York: John Wiley \& Sons.

Manire, S., \& Power, T. (1983). Compliance and the young child: The role of the parents. Paper presented at the the biennial meeting of the Society for Research in Child Development.

Martin, J. (1981). A longitudinal study of the consequence of early mother-infant interaction: A microanalytic aproach. Monographs of the Society for Research and Child Development, 46, 190.

Mazure, C., Keith, G., Blehar, M (2002). Summit on Depression and Women: Proceeding and Recommendations. Washington, DC: American Psychological Association.

McGrath, E., Keita, G. P., Strickland, B. R., \& Russo, N. F. (1990). Women and depression: Risk factors and treatment issues: Final report of the American Psychological Association's National Task Force on Women and Depression. Washington, DC: American Psychological Association. 
McGroder, S. M. (2000). Parenting among low-income African American single mothers with preschool-age children: Patterns, predictors, and developmental correlates. Child Development, 71, 752-771.

Mistry, R. S., Biesanz, J. C., Taylor, L. C., Burchinal, M., \& Cox, M. J. (2004). Family Income and Its Relation to Preschool Children's Adjustment for Families in the NICHD Study of Early Child Care. Developmental Psychology, 40, 727-745.

Mistry, R. S., Vandewater, E. A., Huston, A. C., \& McLoyd, V. C. (2002). Economic well-being and children's social adjustment: The role of family process in an ethnically diverse low-income sample. Child Development 73, 935-951.

Murray, L., \& Cooper, P. (1997). Postpartum depression and child development. New York, NY: Guilford Press.

Murray, L., \& Cooper, P. J. (1997). The role of infant and maternal factors in postpartum depression, mother-infant interactions, and infant outcome. New York, NY: Guilford Press.

Murray, L., Halligan, S. L., Adams, G., Patterson, P., \& Goodyer, I. M. (2006). Socioemotional development in adolescents at risk for depression: The role of maternal depression and attachment style. Journal of Clinical Psychology, 55, 120-130.

Murray, L., Stanley, C., Hooper, R., King, F., \& et al. (1996). The role of infant factors in postnatal depression and mother-infant interactions Developmental Medicine \& Child Neurology, 38, 109-119. 
Murray, V., \& Brody, G. (1999). Self-regulation and self-worth of Black children reared in economically stressed, rural, single mother-headed families: The contribution of risk and protective factors. Journal of Family Issues, 20, 458-484.

Murry, V. M., Bynum, M. S., Brody, G. H., Willert, A., \& Stephens, D. (2001). African American single mothers and children in context: A review of studies on risk and resilience. Clinical Child and Family Psychology Review, 4, 133-155.

Myers, H. F., Lesser, I., Rodriguez, N., Mira, C. B., Hwang, W.-C., Camp, C., et al. (2002). Ethnic differences in clinical presentation of depression in adult women. $8,138-156$.

NICHD. (1999). Chronicity of maternal depressive symptoms, maternal sensitivity, and child functioning. Developmental Psychology, 35, 1297-1310.

Nolen-Hoeksema, S. (1990). Sex differences in depression: (1990). Sex differences in depression.

Petterson, S. M., \& Albers, A. B. (2001). Effects of poverty and maternal depression on early child development. Child Development, 72, 1794-1813.

Pianta, R., \& Caldwell, C. (1990). Stability of externalizing symptoms from kindergarten to first grade and factors related instability. Development and Psychopathology, 2, $247-258$.

Poverty, N. C. f. C. i. (2009). "Social-emotional Development in Early Childhood: What Policymakers Should Know.". Retrieved Dec 20, 2009, from http://www.nccp.org. 
Radke-Yarrow, M., Cummings, E. M., Kuczynski, L., \& Chapman, M. (1985). Patterns of attachment in two- and three-year-olds in normal families and families with parental depression. Child Development, 56, 884-893

Radloff, L. S. (1977a). The CES-D Scale: A self-report depression scale for research in the general population. Applied Psychological Measurement, 1, 385-401.

Reed, M. K., McLeod, S., Randall, Y., \& Walker, B. (1996). Depressive symptoms in African-American women. Journal of Multicultural Counseling and Development 24, 6-14.

Rickel, A., \& Biasatti, L. (1982). Modification of the block child rearing practices report. Journal of Child Psychology, 38, 129-134.

Riley, A., Coitro, M., Broitman, M., Calantuoni, E., Hurley, K., Bandeen-Roche, K., et al. (2009). Mental health of children of low-income depressed mothers: Influences of parenting, family environment, and raters. Psychiatric Services, 60, 329-336.

Rollins, B., \& Thomas, D. (1979). Parental support, power, and control techniques in the socialization of children. In W. R. Burre, R. Hill, F. I. Nye \& I. L. Riess (Eds.), Contemporary thoeries about the family: Research-based thoeries (pp. 317-364). New York: The Free Press.

Slater, M., \& Power, T. (1987). Multidimensional assessment of parenting in singleparent families. Advances in Family Intervention, Assessment and Theory., 4, 197-228.

Snowden, L. R. (2005). Racial, Cultural and Ethnic Disparities in Health and Mental Health: Toward Theory and Research at Community Levels. American Journal of Community Psychology, 35, 1-8. 
Spieker, S. J., \& Booth, C. L. (1988). Maternal antecedents of attachment quality. Hillsdale, NJ, England: Lawrence Erlbaum Associates, Inc.

Supplee, L., Shaw, D., Hailstones, K., \& Hartman, K. (2004). Family and child influences on early academic and emtion regulatory behaviors. Journal of School Psychology, 42, 221-242.

Tamis-LeMonda, C. S., Bornstein, M. H., \& Baumwell, L. (2001). Maternal responsiveness and children's achievement of language milestones. Journal of School Psychology, 55, 748-767.

Taylor, R. D., Seaton, E., \& Dominguez, A. (2008). Kinship support, family relations, and psychological adjustment among low-income African American mothers and adolescents. Journal of Research on Adolescence, 18, 1-22.

U.S. Department of Health and Human Services, O. o. t. S. G., SAMHSA. (1999).

Culture, Race, and Ethnicity A Supplement to Mental Health: A Report of the Surgeon General Retrieved December 12, 2009, from http://mentalhealth.samhsa.gov/default.asp.

van Ijzendoorn, M. H., Juffer, F., \& Duyvesteyn, M. G. C. (1995). Breaking the intergenerational cycle of insecure attachment: A review of the effects of attachment-based interventions on maternal sensitivity and infant security. Social Development, 4, 225-248.

van ljzendoorn, M. H., Schuengel, C., \& Bakermans-Kranenburg, M. J. (1999).

Disorganized attachment in early childhood: Meta-analysis of precursors, concomitants, and sequelae. Development and Psychopathology, 55, 200-215 
Waite, R., \& Killian, P. (2007). Exploring depression among a cohort of African American women. Journal of the American Psychiatric Nurses Association, 13, $161-169$

Warren, B. J. (1994). Depression in African - American Women Journal of Psychosocial Nursing 32(3), 29-32.

Warren, B. J. (2002). The interlocking paradigm of cultural competence: A best practice approach. Journal of the American Psychiatric Nurses Association, 8, 209-213.

Webster-Stratton, C. (1998). Preventing conduct problems in Head Start Children: Strengthening parenting competencies. Journal of Consulting and Clincal Psychology, 66, 715-730.

Weissman, M., Bruce, M., Leaf, P., Florion, L., \& Holzer, C. (Eds.). (1991). Psychiatric disorders in America: The Epidemiological Catchment Area Study. New York: Free Press.

Wildeman, C. (2007). Parental Imprisonment, the Prison Boom and the Concentration of Childhood Disadvantage. Retrieved February 11, 2009, from http://paa2007.princeton.edu/download.aspx?submissionId=7180.

Wilon, S., Bennett, L., \& Jacobs, J. (1992). Assessing family rituals in alcoholic families. In E. Imber-Black, J. Roberts \& R. Whiting (Eds.), Rituals in families and family therapy (pp. 230-256). New York: Norton.

Worthington, C. (1992). An examination of factors influencing the diagnosis and treatment of Black patients in the mental health system. Archives of Psychiatric Nursing, 6, 195-204. 
Wright, M. O. D., \& Masten, A. S. (Eds.). (2005). Resilience Processes in Development: Fostering Positive Adaptation in the Context of Adversity. New York: Springer.

Zahn-Waxler, C., Iannotti, R. J., Cummings, E. M., \& Denham, S. (1990). Antecedents of problem behaviors in children of depressed mothers. Development and Psychopathology, 2, 271-291.

Zahn-Waxler, C., Klimes-Dougan, B., \& Slattery, M. J. (2000). Internalizing problems of childhood and adolescence: Prospects, pitfalls, and progress in understanding the development of anxiety and depression. Development and Psychopathology, 12, 443-466.

Zins, J., Weissberg, R., Wang, M., \& Walberg, H. (Eds.). (2004). Building academic success on social and emotional learning: What does the research say? New York: Teachers College Press. 
Table 1: Demographic Data of Sample Population $(n=103)$

\begin{tabular}{|c|c|c|}
\hline & Percentage \\
\hline \multirow[t]{2}{*}{ Gender: } & Male & 41.7 \\
\hline & Female & 58.3 \\
\hline \multirow[t]{4}{*}{ Age: } & $12-17$ & 28.1 \\
\hline & $18-23$ & 11.7 \\
\hline & $24-29$ & 21.3 \\
\hline & $30-36$ & 38.9 \\
\hline \multirow[t]{5}{*}{ Marital Status: } & Single & 78.6 \\
\hline & Unmarried Partner & 8.7 \\
\hline & Married & 7.8 \\
\hline & Divorced & 3.9 \\
\hline & Unlisted & 1.0 \\
\hline \multicolumn{2}{|c|}{ Education of Caregiver: Grade School } & 1.9 \\
\hline & $9^{\text {th }}$ Grade & 2.9 \\
\hline & $10^{\text {th }}$ Grade & 7.8 \\
\hline & $11^{\text {th }}$ Grade & 19.4 \\
\hline & High School Grad. & 19.4 \\
\hline & Some College & 37.9 \\
\hline & College Grad. & 8.7 \\
\hline & Post-Grad./above & 1.9 \\
\hline \multirow[t]{5}{*}{ Employment Status: } & Full Time & 21.4 \\
\hline & Part Time & 16.5 \\
\hline & $\begin{array}{l}\text { Not employed due } \\
\text { to a disability }\end{array}$ & 2.9 \\
\hline & Unemployed & 56.3 \\
\hline & Unlisted & 2.9 \\
\hline \multirow[t]{7}{*}{ Annual Income: } & $\$ 8,859$ or below & 53.4 \\
\hline & $\$ 8,860-11,939$ & 9.7 \\
\hline & $\$ 11,940-15,019$ & 8.7 \\
\hline & $\$ 15,020-18,099$ & 6.8 \\
\hline & $\$ 18,099-21,179$ & 2.9 \\
\hline & $\$ 21,180-24,259$ & 1.9 \\
\hline & $\$ 24,260-27,339$ & 1.0 \\
\hline
\end{tabular}




\begin{tabular}{|c|c|c|}
\hline & $\$ 27,340-30,419$ & 2.9 \\
\hline & $\$ 30,420-49,999$ & 7.8 \\
\hline & $\$ 50,000-74,999$ & 3.9 \\
\hline & $\$ 100,000$ or above & 1.0 \\
\hline Relation to child: & Mother & 86.4 \\
\hline & Grandmother & 6.8 \\
\hline & Aunt & 3.9 \\
\hline & Other & 2.9 \\
\hline
\end{tabular}


Table 2. Means (and Standard Deviations) of Caregiver and Outcome Measures

\begin{tabular}{lc}
\hline \multicolumn{1}{c}{ Variable } & Mean (SD) \\
\hline Maternal Depression CES-D & $17.32(10.87)$ \\
Parenting Strategies: AAPI-2 & $3.98(1.27)$ \\
Parenting Strategies: Family Routines (FRI) & $20.26(4.17)$ \\
Child Outcome - Social Emotional Behavior & $14.78(8.90)$ \\
BITSEA Problem Scale & $17.49(2.97)$ \\
\hline
\end{tabular}

Center for Epidemiological Studies- Depression (CES-D) is on a scale of 0 and 60 (scores between 16 and 26 are indicative of mild depression and 27 and higher indicative of higher levels of depressive symptoms).

Adult Adolescent Parenting Inventory AAPI-2 measures a number of variables related to parent support and control. Scores between 1-3 are considered high risk for abuse, 4-7 moderate risk for abuse, and 8-10 are considered positive and nurturing parents.

Family Routine Inventory measures frequency of repeated family activities and is on a scale from 0 to 32 . BITSEA Problem Scores are on a scale of 0-49 and BITSEA Competence Scores are on a scale from 1-11. 
Table 3. Intercorrelations among BITSEA Child Assessment (Social-Emotional Problem Scale \& Social-Emotional Competence Scale) and Parental Measures

\begin{tabular}{|c|c|c|c|c|c|c|c|c|c|}
\hline Measure & 1 & 2 & 3 & 4 & 5 & 6 & 7 & 8 & 9 \\
\hline 1. CES-D & -- & $.85^{* *}$ & -.09 & $.44^{* *}$ & .10 & $-.27 * *$ & .13 & .14 & -.03 \\
\hline 2. CES-D Subscale & & -- & -.05 & $.38^{* *}$ & -.12 & $-.29 * *$ & .14 & .12 & -.06 \\
\hline 3. FRI & & & --- & -.14 & $.27^{* *}$ & .18 & .03 & .07 & .01 \\
\hline 4. BITSEA PS & & & & --- & $-.23^{*}$ & $-.31 * *$ & -.05 & .09 & .03 \\
\hline 5. BITSEA CS & & & & & -- & .18 & -.01 & .07 & -.07 \\
\hline 6. AAPI-2 & & & & & & --- & $-.21^{*}$ & .01 & -.04 \\
\hline 7. Child's Age & & & & & & & ... & -.01 & 01 \\
\hline 8. MD x FRI & & & & & & & & --- & 17 \\
\hline 9. MD x AAPI-2 & & & & & & & & & --- \\
\hline$M$ & 17.32 & 4.10 & 20.26 & 14.78 & 17.49 & 3.98 & 25.27 & -3.81 & 3.72 \\
\hline$S D$ & 10.87 & 3.33 & 4.17 & 8.9 & 2.97 & 1.27 & 9.24 & 43.1 & 13.89 \\
\hline
\end{tabular}

Note: CES-D $=$ Center for Epidemiologic Studies - Depression; FRI $=$ Family Routine Inventory; BITSEA = Brief Infant Toddler Social and Emotional Assessment; BITSEA PS = Brief Infant Toddler Social and Emotional Assessment - Problem Score; BITSEA CS = Brief Infant Toddler Social and Emotional Assessment - Competency Score; AAPI-2 = Adult Adolescent Parenting Index 2; MD = Maternal Depression (as measured by CES-D). ${ }^{*} p<.05, * * p<.01$. 
Table 4: Summary of Caregivers' Depressive Symptoms in Sample Population $(n=103)$. Depression was measured using the Center for Epidemiological Studies - Depression (CES-D)(Radloff, 1977)

\begin{tabular}{ccc}
\hline Categories of CES-D Scores & Frequency & $\begin{array}{c}\text { Range of Scores in } \\
\text { Sample Population }\end{array}$ \\
\hline None $(0-15)$ & 54 & $2-15$ \\
Mild $(16-26)$ & 31 & $16-26$ \\
Severe $(27-60)$ & 18 & $27-46$
\end{tabular}

Center for Epidemiological Studies- Depression (CES-D) is on a scale of 0 and 60 (scores between 16 and 26 are indicative of mild depression and 27 and higher indicative of higher levels of depressive symptoms). $M=17.32, S D=10.87$ for this sample population. 
Table 5: Summary of Caregivers' Parent Support and Control Score in Sample Population $(n=103)$. Parent Support and Control was measured using the AdultAdolescent Parenting Index-2.

\begin{tabular}{|c|c|c|}
\hline $\begin{array}{l}\text { Categories of AAPI-2 } \\
\text { sten scores }\end{array}$ & Frequency & $\begin{array}{l}\text { Range of Scores } \\
\text { in Sample Population }\end{array}$ \\
\hline
\end{tabular}

High Risk for abusive parenting

$$
(1-3)
$$

Moderate Risk for abusive parenting $(4-7)$

Positive and nurturing parenting $(8-10)$
42

$2-3$

61

$4-7$

Adult Adolescent Parenting Inventory - 2 (AAPI-2) measures a number of variables related to parent support and control. The 5 categories are: expectations of children; parental empathy towards children's needs; use of corporal punishment; parent-child family roles; and children's power and independence. $M=3.98 S D=1.27$. 
Table 6: Summary of Hierarchical Regression Analysis for Predicting Social-Emotional Problems $(N=103)$.

\begin{tabular}{|c|c|c|c|}
\hline Variable & $\mathrm{B}$ & SE B & $\beta$ \\
\hline \multicolumn{4}{|l|}{ Step 1} \\
\hline Annual Household Income & -1.21 & .27 & $-.41^{* *}$ \\
\hline \multicolumn{4}{|l|}{ Step 2} \\
\hline Annual Household Income & -.99 & .25 & $.33^{* *}$ \\
\hline Maternal Depression & .30 & .07 & $.37 * *$ \\
\hline \multicolumn{4}{|l|}{ Step 3} \\
\hline Annual Household Income & -.91 & .25 & $-.31 * *$ \\
\hline Maternal Depression & .27 & .07 & $.33^{* *}$ \\
\hline Family Routine Inventory & -.16 & .18 & -.08 \\
\hline $\begin{array}{l}\text { Parent Support and Control } \\
\text { (AAPI-2) }\end{array}$ & -.98 & .62 & -.14 \\
\hline \multicolumn{4}{|l|}{ Step 4} \\
\hline Annual Household Income & -.92 & .26 & $-.31^{* *}$ \\
\hline Maternal Depression & .27 & .07 & $.33^{* *}$ \\
\hline Family Routine Inventory & -.16 & .18 & -.08 \\
\hline $\begin{array}{l}\text { Parent Support and Control } \\
\text { (AAPI-2) }\end{array}$ & -.97 & .63 & -.14 \\
\hline MD X FR & -.00 & .02 & -.01 \\
\hline MD X AAPI-2 & .03 & .01 & .04 \\
\hline
\end{tabular}


Table 7: Summary of Hierarchical Regression Analysis for Predicting Social-Emotional Competence Scale $(N=103)$.

Variable

B

SE B

$\beta$

Step 1

Child's Gender

Step 2

Child's Gender

Maternal Depression

Step 3

Child's Gender

Maternal Depression

Family Routine Inventory

Parent Support and Control
1.19

1.26

$-0.3$

1.22

$-.02$

.18

.24
.59

.59

.03

.57

.03

.07

.23

.58

.03

.07

.24
.22

1.23

$-.02$

.17

Parent Support and Control

(AAPI-2)

MD X FR

.01

.01

$.20 *$

MD X AAPI

.02

.02

$.21 *$

$-.09$

$.24^{*}$

.09

Note. $\mathrm{R}^{2}=4.0 \%$ for Step $1(p=.04) ; \Delta \mathrm{R}^{2}=1.4 \%$ for Step $2(p=.23) ; \Delta \mathrm{R}^{2}=7.8 \%$ for Step $3(p=.02) ; \Delta \mathrm{R}^{2}=1.2 \%$ for Step $4(p=.52)$

${ }^{*} p<.05 ;{ }^{* *} p<.01$ 
Table 8: Summary of Hierarchical Regression Analysis for Predicting Social-Emotional Problems in Depressed Caregivers $(N=49)$.

\begin{tabular}{|c|c|c|c|}
\hline Variable & B & SE B & $\beta$ \\
\hline \multicolumn{4}{|l|}{ Step 1} \\
\hline Annual Household Income & -1.40 & .42 & $-.44 * *$ \\
\hline \multicolumn{4}{|l|}{ Step 2} \\
\hline Annual Household Income & 1.2 & .43 & $-.37^{*}$ \\
\hline Maternal Depression & .25 & .15 & .22 \\
\hline \multicolumn{4}{|l|}{ Step 3} \\
\hline Annual Household Income & -1.9 & .46 & $-.37 * *$ \\
\hline Maternal Depression & .26 & .16 & .24 \\
\hline Family Routine Inventory & -.22 & .27 & -.11 \\
\hline $\begin{array}{l}\text { Parent Support and Control } \\
\text { (AAPI-2) }\end{array}$ & -.34 & 1.00 & -.05 \\
\hline \multicolumn{4}{|l|}{ Step 4} \\
\hline Annual Household Income & -1.17 & .47 & $-.37 *$ \\
\hline Maternal Depression & .29 & .16 & .26 \\
\hline Family Routine Inventory & -.47 & .46 & -.24 \\
\hline $\begin{array}{l}\text { Parent Support and Control } \\
\text { (AAPI-2) }\end{array}$ & 1.01 & 1.60 & -.14 \\
\hline MD X FR & .03 & .04 & .16 \\
\hline MD X AAPI-2 & .07 & .13 & .17 \\
\hline
\end{tabular}


Table 9: Summary of Hierarchical Regression Analysis for Predicting Social-Emotional Competence in Depressed Caregivers $(N=49)$.

\begin{tabular}{llll}
\hline Variable & B & SE B & $\beta$ \\
& & & \\
\hline Step 1 & 1.28 & .82 & .22 \\
$\quad$ Child's Gender & & & \\
Step 2 & 1.35 & .82 & .23 \\
$\quad$ Child's Gender & -.06 & .05 & -.16 \\
$\quad$ Maternal Depression & & & \\
Step 3 & 1.49 & .78 & .26 \\
$\quad$ Child's Gender & -.09 & .05 & -.26 \\
$\quad$ Maternal Depression & .27 & .09 & $.43^{*}$ \\
Family Routine Inventory & -.20 & .32 & -.09 \\
Parent Support and Control & & & \\
$\quad$ AAPI-2) & & & .26 \\
Step 4 & 1.48 & .81 & -.26 \\
$\quad$ Child's Gender & .09 & .05 & $.46^{*}$ \\
Maternal Depression & .30 & .15 & -.10 \\
Family Routine Inventory & -.22 & .52 & -.05 \\
Parent Support and Control & & .01 & .02 \\
$\quad$ AAPI-2) & -.00 & .04 & \\
MD X FR & .00 & & \\
$\quad$ MD X AAPI-2 & &
\end{tabular}




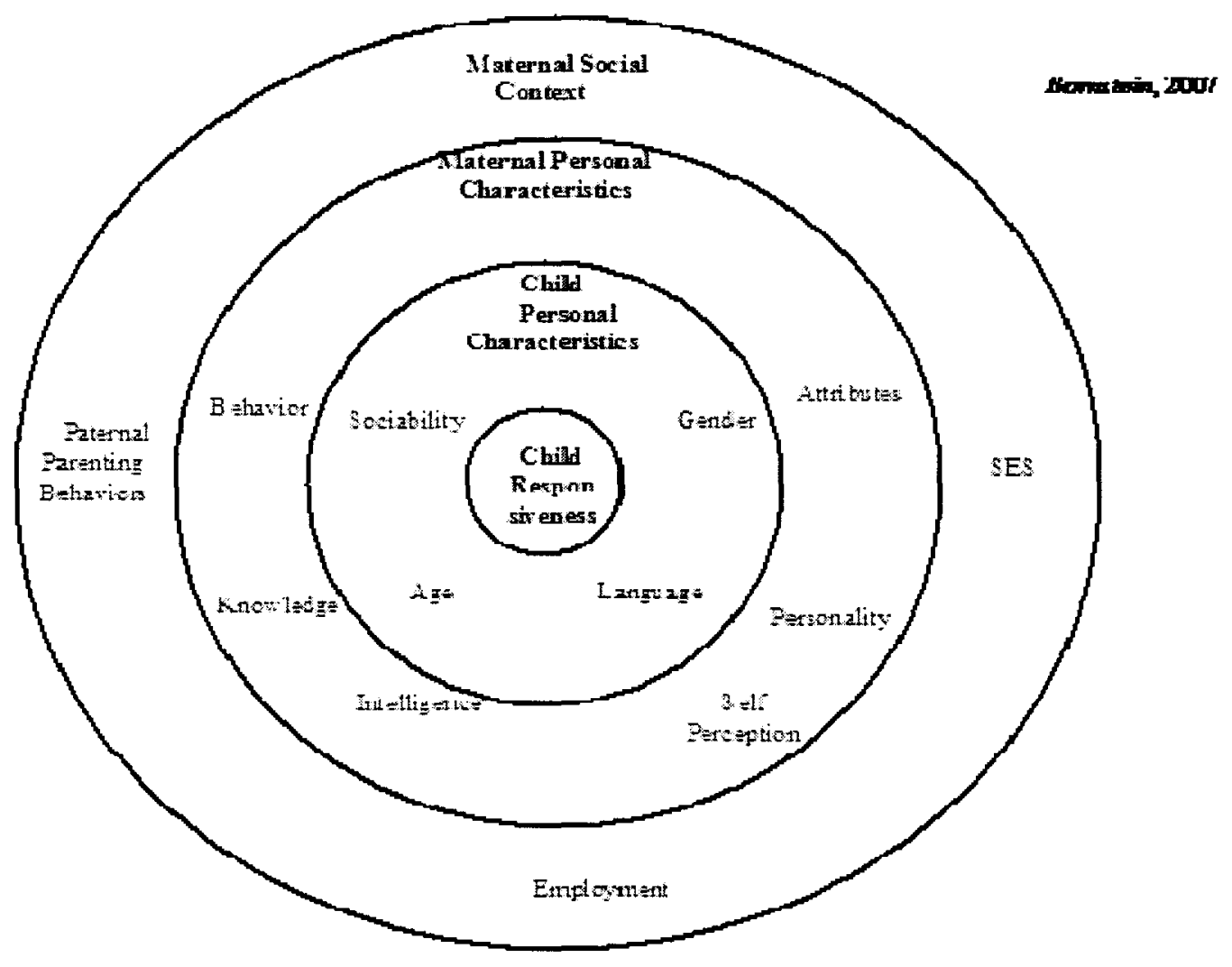

Figure1. Hypothetical model of relations among maternal social context, maternal sensitivity, and maternal characteristics and child personal characteristics (Bornstein et al., 2007) 




Fig. 2 Hypothetical model of relationship between mother and child for current study. 
Figure 3: Summary of Caregivers' Depression Scores.

\section{Depression Scores of Sample Population}

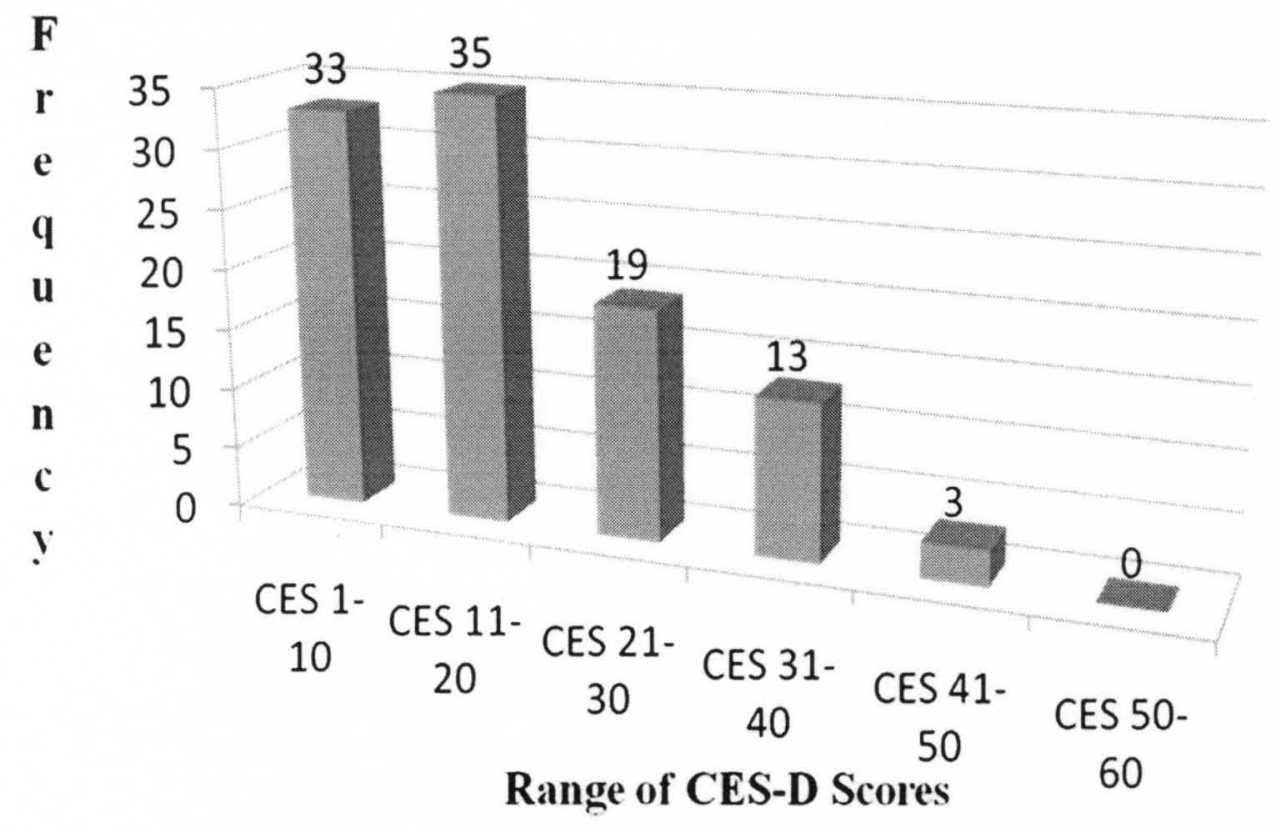

Depression was measured using the CES-D. The scale is: 1-15 no depression ; 16-26 mild depression: 27-60 severe depression.

Figure 3: Summary of Caregivers' Depression Scores. 
Appendix A

\section{PARENT INFORMATION FORM}

Please complete the following information about the household in which the child participating in the study lives most of the time (greater than half the time).

1. How many adults (18 or older) including yourself live in the household?

2. How many children (under 18) including the child being studied live in the household?

3. Think of all of the income from persons living in the same house as the child being studied. Which category below best describes your household income for the last 12 months?
a. $\$ 8,859$ or below
b. $\$ 8,860-\$ 11,939$
c. $\$ 11,940-\$ 15,019$
d. $\$ 15,020-\$ 18,099$
e. $\$ 18,100-\$ 21,179$
f. $\$ 21,180-\$ 24,259$
g. $\$ 24,260-\$ 27,339$
h. $\$ 27,340-\$ 30,419$
i. $\$ 30,420-\$ 49,999$
j. $\$ 50,000-\$ 74,999$
k. $\$ 75,000-\$ 100,000$
1. $\$ 100,000$ or above

4. In terms of your "typical" household income, how would you describe your income for the last 12 months?
a. Much less than usual.
b. Somewhat less than usual
c. About the same as usual
d. Somewhat more than usual
e. Much more than usual

5. In the last 12 months, did your household receive any of the following kinds of income? Please check all that apply Unemployment compensation Disability (Workman's Compensation or Social Security) 
Welfare (including Aid to Families with Dependent Children)

Support or alimony from ex-spouse

Food stamps

Medicaid

Public housing

WIC (Women, Infants, and Children) food vouchers

Other public assistance (specify)

6. Please indicate the level of education completed by the child's mother or mother figure living in the household.

Primary grades $\quad 6 \quad 7 \quad 8$

$\begin{array}{lllll}\text { High School } & 9 & 10 & 11 & 12\end{array}$

POST HIGH SCHOOL (Please check all that apply) attended

received

degree/diploma

Vocational school

2-year college

4-year college

Graduate/professional school (above a 4-year degree)

(specify)

Other (specify; be specific)

7. Please indicate the level of education completed by the child's father or father figure living in the household.

$\begin{array}{llll}\text { Primary grades } & 6 & 7 & 8\end{array}$

$\begin{array}{lllll}\text { High School } & 9 & 10 & 11 & 12\end{array}$

POST HIGH SCHOOL (Please check all that apply) attended received degree/diploma

Vocational school

2-year college 
4-year college

Graduate/professional school (above a 4-year degree)

(specify)

Other (specify; be specific)

8. Please describe the occupation of the child's mother or mother figure living in the home. (Be specific)

9. Please describe the occupation of the child's father or father figure living in the home. (Be specific)

10. Which of the following descriptions best describe the work pattern of the primary support person in the household?

a. Not working due to family care responsibilities

b. Not working due to own health problems or disabilities

c. Unemployed because can't find work

d. Works whenever work is available

e. Works steady or regular part-time job

f. Works full-time job

11. What is the age of the child's mother?

12. What is the age of the child's father? 


\section{Appendix B}

\section{CES-D}

Below is a list of the ways you might have felt or behaved. Please tell us how often you have felt this way durng the past week.

Rarefy or none of the time = less than 1 day

Some or a little $=1-2$ days

Occasionally $=3-4$ days

Most ar all of the time

\begin{tabular}{|c|c|c|c|c|c|}
\hline & & $\begin{array}{l}\text { Revely or } \\
\text { not at all }\end{array}$ & $\begin{array}{l}\text { Bome or } \\
\text { a litile }\end{array}$ & Occasionally & $\begin{array}{c}\text { Most or } \\
\text { all the } \\
\text { tme }\end{array}$ \\
\hline 1 & $\begin{array}{l}\text { I was bothered by things that usually don't } \\
\text { bother me. }\end{array}$ & & & & \\
\hline 2 & $\begin{array}{l}\text { I dd not feel like eating, my appette was } \\
\text { poor. }\end{array}$ & & & & \\
\hline 3 & $\begin{array}{l}\text { I felt that I couid not shake off the blues even } \\
\text { wh help from my frends and family. }\end{array}$ & & & & \\
\hline 4 & I helt that I was just as good as other people. & & & & \\
\hline 6 & $\begin{array}{l}\text { I had trouble keeping my mind on what I was } \\
\text { doing. }\end{array}$ & & & & \\
\hline 6 & I fell deptessed. & & & & \\
\hline 7 & Ifelt that everything I did was an effort & & & & \\
\hline 8 & I telt hopeful about the future & & & & \\
\hline 8 & I thought my ife had been a fallure & & & & \\
\hline 10 & I felt fearful & & & & \\
\hline 11 & My sleep was restless. & & & & \\
\hline 12 & I was happy & & & & \\
\hline 13 & I talked less than usual. & & & & \\
\hline 14 & I felt lonely. & & & & \\
\hline 15 & People were untriendly. & & & & \\
\hline 16 & 1 enjoyed life. & & & & \\
\hline 17 & I had cring spells & & & & \\
\hline 18 & lfels sad. & & & & \\
\hline 19 & Itell that people disliked me. & & & & \\
\hline 20 & I could not get "going." & & & & \\
\hline
\end{tabular}




\section{AAPI OnLine \\ Adult-Adolescent Parenting Inventory (AAPI-2) \\ Test Form A}

This test can only be scored online at www.aapionline.com

Stephen 3. Bavolek, Pn.D. and Richare G. Keene, Pn.D.

Before you take the inventory, we need some important information from you.

1. Date:

2. First Name:

3. Middle Initial (optional):

4. Last Name:

5. Bithday

Month

Day

Year

6. Gender: 5 Male 0 Female


If "Other" please specify:

8. Marital Status: J Divorced O Martied o single O unmarried Partners o Don't know

9. How many children do you have:

10. What is the highest grade you completed in school: J Grade School

$27^{\text {th }}$ Grade

$211^{\text {tr }}$ Grade

$8^{\text {th }}$ Grade

DHigh School Graduate

$3 g^{\text {tk Grade }}$

D some college

$210^{\text {th }}$ Grade

College Graduate

$\partial$ post-Graduate or Above

11. What is your employment status:

$$
\begin{aligned}
& 3 \text { Don't know } \\
& 2 \text { Employed Full Time } \\
& 2 \text { Employed Part Time }
\end{aligned}
$$

Not Employed Because of Disability

O Unemployed

Retired

12. What is your annual household income: O Under $\$ 15,000$

D $\$ 15,001-\$ 25,000$

$\$ 25,001-\$ 40,000$

$\$ 40,001-\$ 60,000$

Dover $\$ 60,000$

13. Were you andior your partner in the military: 9 No

3 res, both of us

$\partial$ Yes, only me

2 Yes, only my partner

$\rho$ Don't know

14. As a child, did you experience any type of abuse by a person: Outside your family? 3 No 2 yes Within your famlly? D No D Yes

(800) 683-5822 * (435) 649-5822 ioutside the Urited States) * forarurturingarenting.com www.aapionline.com

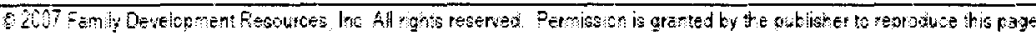




\section{Appendix D}

\section{Family Routine}

\section{Work Day Routines}

1. Parent(s) have some time each day for just talking with the children.

$\begin{array}{ccccc}0 & 1 & 2 & 3 & 4 \\ \text { Not } & \text { Almost } & \text { Sometimes } & \text { Often } & \text { Almost } \\ \text { Applicable } & \text { Never } & & & \text { Always }\end{array}$

2. Parent(s) have certain things they do every morning while getting ready to start the dary.

$\begin{array}{ccccc}0 & 1 & 2 & 3 & 4 \\ \text { Not } & \text { Alnost } & \text { Sometimes } & \text { Often } & \text { Almost } \\ \text { Applicable } & \text { Never } & & & \text { Always }\end{array}$

3. Working parent(s) has a regular play time with the children after coming home from work.

$\begin{array}{ccccc}0 & 1 & 2 & 3 & 4 \\ \text { Not } & \text { Nimost } & \text { Sometimes } & \text { Often } & \text { Almost } \\ \text { Applicable } & \text { Never } & & & \text { Always }\end{array}$

4. Working parent(s) takes care of the children some time every day.

$\begin{array}{ccccc}0 & 1 & 2 & 3 & 4 \\ \text { Not } & \text { Almost } & \text { Sometimes } & \text { Often } & \text { Almost } \\ \text { Applicable } & \text { Never } & & & \text { Always }\end{array}$

5. Children do the same things every morning as soon as they wake up.

$\begin{array}{ccccc}0 & 1 & 2 & 3 & 4 \\ \text { Not } & \text { Almast } & \text { Sometimes } & \text { Often } & \text { Almost } \\ \text { Applicable } & \text { Never } & & & \text { Always }\end{array}$

6. Parent(s) and children play together some time each day.

$\begin{array}{ccccc}0 & 1 & 2 & 3 & 4 \\ \text { Not } & \text { Almost } & \text { Sometimes } & \text { Often } & \text { Almost } \\ \text { Applicable } & \text { Never } & & & \text { Always }\end{array}$


7. Non-working parent and children do something together outside of the home every day (i.e. shopping. walking).

\begin{tabular}{|c|c|c|c|c|}
\hline 0 & 1 & 2 & 3 & 4 \\
\hline Not & Almosi & Sometimes & Often & Almos: \\
\hline Applicable & Never & & & Always \\
\hline
\end{tabular}




\section{Appendix E}

\section{Sample Items from the BITSEA}

Please circle the answer the that best describes your child in the last month.

0 : Not True or Rarely

1: Somewhat true or Sometimes

2: Very True or Often

$\mathrm{N}$ : No Opportunity (Circle if you have not had the opportunity to observe

1. Shows pleasure when he/ she succeeds (For example, claps for self)........ 12

9. Has less fun than other children ......... 1

14. Cries or hangs on to you when you try to leave..... $1 \quad 1 \quad 2$

17. Does not react when hurt......0 $1 \quad 2$

21. Runs away in public places...... $\quad 1 \quad 2$

23. Plays well with other children (not included brother/ sister).......0 $1 \quad 1 \quad 2$ ( $\mathrm{N}=$ no contact) 
Appendix F

Items from the CES-D used to measure, somatic depressive symptoms of African American Caregivers.

1. I do not feel like eating today, my appetite was poor.

2. I was bothered by things that usually do not bother me. .

3. I had trouble keeping my mind on what I was doing. .

4. I felt that everything was an effort. .

5. I could not get "going".

6. I talked less than usual. 


\section{CURRICULUM VITAE \\ PAULETTE A. FLORES Ph.D. \\ Permanent Address \\ 151 Weslee Way Apt. 5 \\ Hazard, KY. 41701 \\ (502) 640-1902 \\ paflor02@louisville.edu}

\section{PERSONAL INFORMATION}

Date of Birth: December 01, 1970

Citizenship: Belizean

Languages Spoken: English, Garifuna, Belizean English-based Creole

\section{EDUCATION}

2011

2003-2007 University of Louisville, Louisville, KY

M.A. Clinical Psychology

M.A. General Psychology

1994-1997

University of Belize, Belize City, Belize

B.A. English Education

1990-1993

Belize Teachers' Training College/ University of the West Indies, Belize City Campus, Belize

Certificate in Teacher Training

\section{CLINICAL EXPERIENCES:}

August 2010- Present

\author{
Appalachian Rural Consortium \\ Hazard, KY \\ Predoctoral Internship in Clinical \\ Psychology \\ American Psychological Association- \\ accredited internship
}


American Psychological Associationaccredited internship

February 2011- Present

Primary Rotation: Appalachian Regional Healthcare Psychiatric Center

- Collaborate with a multidisciplinary team on the treatment planning of patients with a wide array of mental illnesses including chronic mental illness, PTSD, substance abuse, mood disorder, personality disorder, elderly with dementia and other mental illnesses.

- Provide culturally sensitive individual therapy for adults in a rural setting.

- Create and implement treatment plans with individual patients to direct their course of treatment.

- Facilitate empirically-validated group therapy on a weekly basis on Healthy Relationships, Coping with Depression, Decreasing Suicidal Thoughts and Making Friends.

- Administer, score and interpret psychodiagnostic assessments administered to patients and providing feedback to multidisciplinary team.

February 2011 - Present

Minor Rotation: Appalachian Regional Healthcare Medical Center, Bariatric Clinic

- Psychologically assess clients for lap band procedure, gastric sleeve and gastric bypass surgery using structured interview, and personality testing.

August 2010 - January 2011

Primary Rotation: Kentucky River Community Care

- Provided mental health services to children, adolescents, adults, and developmentally disabled at a non-profit, trauma informed community mental health facility which serves eight counties of Kentucky.

- Provided culturally sensitive long-term and short-term individual therapy to children and adults.

- Conducted semi-structured intake interviews for new clients.

- Assisted emergency and 'walk-in' patients with varying issues and made referrals to agencies and organizations to get the assistance that was necessary.

- Administered, scored, and interpreted psychodiagnostic assessments. Reports were written and feedback given to patients, or referral sources. Battery of assessment typically included: intelligence/ achievement testing; adaptive functioning; ADHD; violence risk assessment; disability; parenting assessment and diagnostic clarification.

- Collaborated with multidisciplinary team in the treatment planning of patients with varied degrees of mental illness. 
- Provided mental health and trauma services to children and adolescents with behavioral issues at a crisis stabilization inpatient facility.

- Conducted individual and group psychotherapy.

- Administered, scored and interpreted psychological assessments. Reports were written and feedback given to referring agencies.

- Consulted with staff about treatment and continuity of care of individual clients.

August 2010-January 2011

Minor Rotation: Bailey Center

- Provided mental health and trauma services to adults with an array of mental illnesses including schizophrenia, personality disorders, chronic mental illness, PTSD, at a crisis stabilization inpatient facility.

- Provided individual and group psychotherapy.

- Conducted ER Triage evaluations.

- Consulted with staff about treatment and continuity of care of individual patients.

August 2010- January 2011

Minor Rotation: ER Triage

- Conducted ER Triage Evaluations on patients from varying areas of Eastern Kentucky with various presenting problems including severe mental illness, suicidal ideations / attempts, substance abuse or dependence, mental retardation, behavioral problems, and psychotic symptoms.

- Made recommendations as to course of treatment for patients being evaluated.

- Communicated treatment recommendations to ER staff and patients.

- Conducted involuntary evaluations and completed necessary legal paperwork.

- Referred patients to other facilities who did not meeting criteria for hospitalization.

October 2010-December 2010

ADDVANCE
Minor Rotation: Project

(Addressing Dimensions of

Domestic Violence and Addiction

Needs through Community Effort)

- Provided mental health and trauma services to women with Dual Diagnosis (substance abuse and trauma) most of whom were non-custodial parents trying to regain custody.

- Provided individual and group psychotherapy on issues such as self-care, addiction, relapse prevention using empirically-based treatment such as Rational Emotive Behavior Therapy.

- Made recommendations about treatment and continuity of care. 
July 2008 - June 2009

\author{
Research Assistant \\ Central State Hospital \\ Louisville, KY
}

- Conducted psychotherapy with individuals using an array of approaches (CBT, ITP, DBT)

- Administered and scored psychodiagnostic assessments administered to patients.

- Assessments administered include: BDI-II, QIDS-SR, suicide risk assessments, MCMIIII, MMPI-2, PAI, WASI, WRAT-III, MMSE, SIRS, M-FAST, DRS, PPVT-III, and SIB-R.

- Composed progress and integrative reports based on clinical interviews, chart reviews and assessments administered.

- Attended multidisciplinary team meetings to discuss direction of treatment for each patient on the unit.

- Reviewed treatment planning with individual patients.

- Conducted group therapy with patients using empirically-based treatments.

September 2008 - December 2008

\author{
Facilitator \\ Intervention to Improve Maternal \\ Sensitivity \\ Seven Counties, \\ Louisville, KY
}

- Conducted ten intervention sessions with mothers with each session being an hour and a half long. Sessions educated mothers about the social-emotional needs of the child and how those needs can be met using sensitive interventions.

- Participated in the planning, creation and implementation of all the materials (weekly powerpoints, handouts, video clips) used to ensure the effectiveness of the intervention.

July 2006

\author{
Counselor \\ Social Skills Summer Camp for \\ Autistic Children \\ Louisville, KY
}

- Assisted children with Autism Spectrum Disorder with activities of daily living;

- Co-facilitated groups to support social skills development. 


\title{
University of Belize \\ Belmopan, Belize
}

- Assisted students in handling crisis situations

- Provided resources for students to seek help in the university environment and in the community at large.

\section{RESEARCH EXPERIENCE:}

July 2007- July 2010

\author{
Research Assistant \\ Early Intervention for Families \\ Lab \\ Department of Psychological and \\ Brain \\ Sciences, University of Louisville
}

- Used SPSS to enter data set addressing parent-child interaction as aspects of Maternal Sensitivity study.

- Coordinated activities for the maternal sensitivity interventions.

- Planned and attended meetings with colleagues from community mental health agencies in the Louisville Metro area.

- Attended training sessions to administer assessments that would be given during the intervention.

July 2006-June 2007

\section{Early Intervention for Families \\ Lab \\ Department of Psychological and Brain}

- Conducted literature searches for numerous topics including early intervention and developmental delays for the production of a New York City Health Bulletin.

- Assisted in the preparation of the manuscript for the City Health Bulletin released in Spring 2008 in New York City.

- Managed the daily activities of the "Early Intervention for Multi-Risk Lab". Planned monthly meetings and managed the electronic communication outlet for the lab. 


\title{
National Institute of Mental \\ Health Grant, Systematic \\ Treatment of Autism and Related \\ Disorders \\ Weisskopf Child Evaluation \\ Center \\ Louisville, KY
}

- Collected, managed and tracked forms which pertained to the National Institutes of Mental Health (NIMH) grant entitled Outcomes of Teacher Training on Autism

- Developed coding manual and used SPSS to organize data for NIMH grant Outcomes of Teacher Training on Autism.

- Administered and scored psychological evaluations (Autism Diagnostic Observation Scale, Differential Abilities Scale, etc.) used as baseline data of children with Autism Spectrum Disorder.

July 2003- June 2005

\author{
Behavioral Oncology, Department \\ of Psychological and Brain \\ Sciences, \\ University of Louisville \\ Louisville, KY
}

- Developed an introduction to a proposal for a study which examined the attitudes of college students towards an HPV vaccine to prevent cervical cancer.

- Used SPSS to enter data on a tobacco prevention program which surveyed health professionals and their level of encouragement to patients to terminate their tobacco habit.

- Conducted literature searches to evaluate the empirical literature pertaining to the human papillomavirus (HPV) vaccine and its receptivity. Examined clinical outcome data.

TEACHING EXPERIENCE:

August 2008 - Present

Lab

\section{Graduate Student Mentor Early Intervention for Families}

University of Louisville

Louisville, KY

- Supervise and instruct 1 to 3 undergraduate research assistants in several areas of psychological research including participant recruitment, data collection, data management, data analysis and presentation of data findings. 
Graduate Teaching Assistant Department of Psychological and Brain Sciences University of Louisville Louisville, KY

- Attended general lecture series and prepared materials for recitation section of courses in the following courses: Experimental Psychology, Quantitative Methods in Psychology, Social Psychology, and Introduction to Psychology.

- Constructed examinations, conducted review sessions, and proctored examinations for classes with over a hundred undergraduates.

- Grading responsibilities included maintenance of grades database.

- Guided students in planning and implementation of research projects.

June 2000- May 2002

\author{
Associate Lecturer \\ Regional Language Center \\ University of Belize \\ Belmopan, Belize
}

- Taught English as a Second Language courses to hundreds of students from Latin and South America.

- Oriented students with the Belizean culture by taking them on trips, and engaging them in community projects and volunteer activities.

July 1994-June 2000

\author{
Secondary School Teacher \\ Methodist Mission \\ Belize City, Belize
}

- Planned and presented course and evaluative materials in English language for students in the first three years of high school.

- Prepared seniors for external exams in English Literature.

\title{
PUBLICATIONS
}

Burns, B., Clancy, J. Amgott, M., Flores, P., Govind, P., Stone, L. (2008) Identifying and referring children with developmental delays to early intervention services. New York City Department of Health and Mental Hygiene, Early Intervention Program, City Health Information. 27, 9-16. 
Day, C., Flores, P. A., \& Burns, B. M. (2008). Early intervention on maternal sensitivity in low-income families: Pilot study (Technical Report). Louisville, KY: University of Louisville, Department of Psychological and Brain Sciences.

Flores, P., Day, C., Richard, H., and Horace, A. (Fall, 2007). Promoting motherchild attachments: Review of the past and recommendations for future interventions. NHSA

Dialog: A Research to Practice Journal for the Early Intervention Field.10, 129142.

\section{MANUSCRIPT IN PREPARATION}

Flores, P., Davis, D., \& Burns, B. (in preparation) Maternal depression and children's attention regulation in low income families. Manuscript in preparation.

\section{POSTERS}

Kremer, C., Flores, P., Bruce, C., Rossman, K., \& Burns, B., (April, 2011 ) Social emotional development in African American toddlers: The role of parenting support and control. Poster will be presented at the Undergraduate Research Symposium, Louisville, KY.

Collins, S., Flores, P., Kremer, C., Rossman, K., \& Burns, B. (April, 2010) Social emotional development in African American toddlers: The role of maternal depression. Poster was presented at the Undergraduate Research Symposium, Louisville, KY.

Dickerson, B., Collins, S., Woodard, S., Rossman, K., Flores, P., Kremer, C., Haynes, L., Burns, B., Day, C., Hubbard, A., \& Spangler, R. (April, 2010) Research and community engagement project for early childhood intervention and school readiness. Poster was presented at the Community Engagement Showcase, Louisville, KY.

Collins, S., Dickerson, B., Woodard, S., Rossman, K., Flores, P., Kremer, C., Haynes, L., Burns, B., Day, C., Hubbard, A., \& Spangler, R (March, 2010) Research and community engagement project for early childhood intervention and school readiness. Poster was presented at the Kentucky Psychological Association Spring Conference, Louisville, KY.

Flores, P., Fister, E., Day, C., \& Burns, B. (2009, April) Development and implementation of a theoretically-based intervention to promote health caregiverchild attachment. Poster was presented at the Kentucky Psychological Association, Lexington, KY. 
Flores, P., Fister, E., Day, C., \& Burns, (2009, April) Development and implementation of a theoretically-based intervention to promote healthy caregiver-child attachment. Poster was presented at the Kentucky Science and Engineering Foundation Conference, Louisville, KY.

Day, C., Jenkins, L., Flores, P., Harris, R., \& Burns, B. (2008, April) The relation of self-evaluative emotions to motivation orientation in preschool-aged children. Poster was presented at the Conference on Human Development Indianapolis, IN.

Flores, P., Gordon, M., Day, C., \& Burns, B. (2008, March) A longitudinal examination of the relation between children's spontaneous verbalizations and the development of motivation. Poster was presented at the Kentucky Psychological Association, Louisville, KY.

Chang, F., Harris, R. \& Flores, P. (2007, March) Characterizing motivation and helplessness in low and middle income children. Poster was presented at Society of Research and Child Development, Boston, MA.

Ruble, L., Flores, P., Mathai G. (2006, October). Effectiveness of a social skills summer camp for children with autism spectrum disorder. Poster was presented at Research Louisville, Louisville, KY. Placed $2^{\text {nd }}$.

\section{PRESENTATIONS}

Davis, D., Flores, P. \& Burns, B. Factors associated with maternal sensitivity in low-income mothers of preschoolers. Presented at Conference on Human Development, Indianapolis, IN. April, 2008.

Burns, B., Flores, P., Day, C., Richards, H., \& Gordon, M. Promoting first relationships.

Presented at Head Start Teacher Training, Louisville, KY. August, 2007.

Mathai, G., Flores, P. \& Ruble, L.(May, 2007). Social skills camp outcomes for children with autism spectrum disorder. International Meeting for Autism

Research, Seattle, WA.

\section{COMMUNITY PRESENTATIONS}

Allison, K., Flores, P., Gordon, M., Hess, L., Rogers, W. \& Zimmerman, J. Maintaining healthy behavior: How to stick with healthy eating. Presentation at Morgan \& Pottinger PSC, Louisville, KY. July, 2008.

\section{WORKSHOPS FOR TEACHERS AND SCHOOLS}


Flores, P., Day, C., Richard, H., Horace, A., \& Burns, B. M. (2007, April).

Promoting First Relationships: Project Proposal. Presented to JCPS Early Head Start Administrative Staff, Louisville, KY.

Flores, P., Day, C., Richard, H., Gordon, M., \& Burns, B. M. (2007, August). Promoting First Relationships. Presented to JCPS Early Head Start Teachers. Louisville, KY.

\section{GRANTS}

Burns, B.M. \& Flores, P. Understanding social-emotional processes in African American toddlers. University of Louisville President's Commission on Diversity and Racial Equality: Research and Diversity Grant (April, 2010).

\section{SPECIALIZED DEVELOPMENTAL TRAINING:}

Promoting First Relationships (PFR) Training Program April 2007

Sponsored by Nursing Child Assessment Satellite Training Program and the University of Washington, Seattle, WA

Autism Diagnostic Observation Scale (ADOS) Training for Clinicians June 2007

Sponsored by the University of Michigan's Autism and Communications Center Ann Arbor, MI 